Boise State University

ScholarWorks

\title{
Hydraulic Tomography: 3D Hydraulic Conductivity, Fracture Network, and Connectivity in Mudstone
}

Claire R. Tiedeman

U.S. Geological Survey

Warren Barrash

Boise State University 


\section{0 \\ NGWA GROUNDWATER FLY-IN}
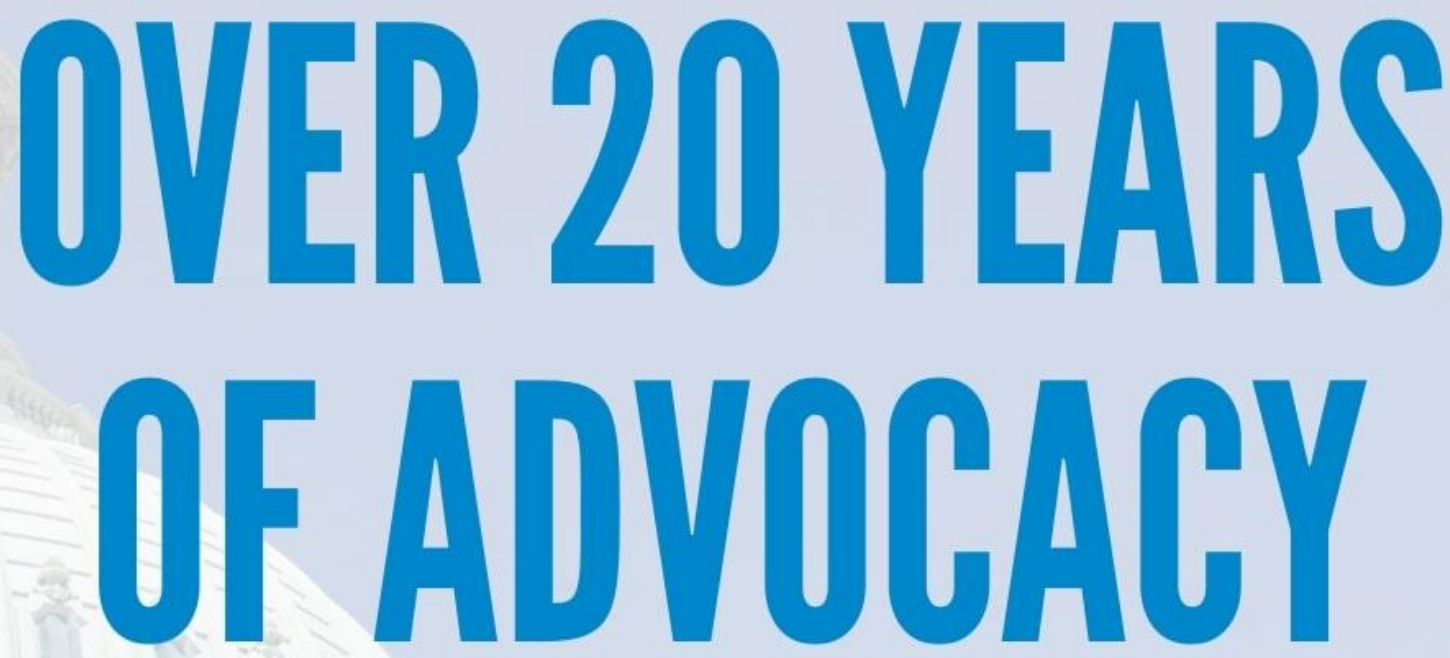

\section{WATER RESOURCES CONGRESSIONAL SUMMIT}

\section{MARCH 3-4, 2020}

Under joint sponsorship with the Irrigation Association and the Water Quality Association, the 2020 NGWA Groundwater Fly-In is organized to increase the water industry's profile on Capitol Hill regarding the availability, quality, and safety of our nation's water resources. This event will ensure members of Congress are aware of the important role groundwater plays in providing drinking water, supporting agriculture, and fueling various sectors of the economy.

\section{JOIN US.}

\section{NGWA. ORG/FLYIN}




\title{
Hydraulic Tomography: 3D Hydraulic Conductivity, Fracture Network, and Connectivity in Mudstone
}

\author{
by Claire R. Tiedeman ${ }^{1}$ and Warren Barrash ${ }^{2}$
}

\begin{abstract}
We present the first demonstration of hydraulic tomography (HT) to estimate the three-dimensional (3D) hydraulic conductivity $(K)$ distribution of a fractured aquifer at high-resolution field scale (HRFS), including the fracture network and connectivity through it. We invert drawdown data collected from packer-isolated borehole intervals during 42 pumping tests in a wellfield at the former Naval Air Warfare Center, West Trenton, New Jersey, in the Newark Basin. Five additional tests were reserved for a quality check of $\mathrm{HT}$ results. We used an equivalent porous medium forward model and geostatistical inversion to estimate $3 \mathrm{D} K$ at high resolution ( $K$ blocks $<1 \mathrm{~m}^{3}$ ), using no strict assumptions about $K$ variability or fracture statistics. The resulting 3D $K$ estimate ranges from approximately 0.1 (highest- $K$ fractures) to approximately $10^{-13} \mathrm{~m} / \mathrm{s}$ (unfractured mudstone). Important estimated features include: (1) a highly fractured zone (HFZ) consisting of a sequence of high- $K$ bedding-plane fractures; (2) a low- $K$ zone that disrupts the HFZ; (3) several secondary fractures of limited extent; and (4) regions of very low- $K$ rock matrix. The 3D $K$ estimate explains complex drawdown behavior observed in the field. Drawdown tracing and particle tracking simulations reveal a 3D fracture network within the estimated $K$ distribution, and connectivity routes through the network. Model fit is best in the shallower part of the wellfield, with high density of observations and tests. The capabilities of HT demonstrated for 3D fractured aquifer characterization at HRFS may support improved in situ remediation for contaminant source zones, and applications in mining, repository assessment, or geotechnical engineering.
\end{abstract}

\section{Introduction}

Determining three-dimensional (3D) network geometry and distribution of hydraulic properties (i.e., hydraulic conductivity $[K]$ and specific storage $\left[S_{\mathrm{s}}\right]$ ) in fractured aquifers at high-resolution field scale (HRFS) is a major unsolved problem in hydrologic science and engineering (NRC 2013; NAS 2015). HRFS is defined as investigated volumes of 10 to tens of meters in diameter and aquifer thickness, with hydraulic parameter resolution of $\leq 1 \mathrm{~m}^{3}$. Currently there are no field-demonstrated direct (hydrologic) or indirect (e.g., geophysical) methods, alone or together, capable of accurately estimating (i.e., vs. using interpolation between wells or strict statistical models of

${ }^{1}$ Corresponding author: U.S. Geological Survey, 345 Middlefield Road MS 496, Menlo Park, CA 94025; tiedeman@usgs.gov

${ }^{2}$ Department of Geosciences, Boise State University, Boise, ID 83725

Article impact statement: Hydraulic tomography estimates 3D hydraulic conductivity distribution, fracture network, and connectivity at high-resolution field scale.

Received December 2018, accepted May 2019.

Published 2019. This article is a U.S. Government work and is in the public domain in the USA.

doi: $10.1111 /$ gwat. 12915 fracturing) the in situ 3D fracture network and $K$ distribution at HRFS.

Rough approximations to fractured-aquifer property distributions and behavior are inadequate to solve many high-liability problems (e.g., source-zone contamination, nuclear waste management), resulting in major financial, institutional, and societal burdens - some with time frames estimated in centuries or millennia. Cost estimates in the United States alone exceed $\$ 100$ billion to close sites with contaminated groundwater-where the most difficult sites to remediate are in fractured aquifers (Ehlers and Kavanaugh 2013; Leeson et al. 2013; NRC 2013; NAS 2015). Leaders in the field advocate research "in developing more 'surgical' characterization and remediation methods" to effectively and efficiently remove health and environmental hazards from contaminated fractured sites (Leeson et al. 2013).

Numerous well-established 1D or single-well methods (e.g., core analysis, borehole imaging and other geophysical logs, slug tests, borehole flow logging) and two-dimensional (2D) or cross-hole methods (e.g., hydraulic interference tests, geophysical tomography) provide information on fracture density and orientation, $K$, and relation to lithology-commonly on borehole 
segments isolated with packers (Paillet 1998; Day-Lewis et al. 2006; Wishart et al. 2008; Chapman et al. 2013; NAS 2015). However, all of these methods require spatial interpolation to generate 3D representations of aquifer properties from one-dimensional (1D) and/or 2D analyses and measurements (Butler 2005; Bohling et al. 2007; Deutsch 2007; Castagna and Bellin 2009). When geophysical methods are used, rock physics or petrophysical relations are needed to convert geophysical parameters into hydrologic parameters (e.g., Ellefsen et al. 2002; Rubin and Hubbard 2005; Chen et al. 2006; Linde et al. 2006; Dafflon et al. 2011).

Similarly, methods for estimating 3D fracturenetwork geometry, connectivity, and hydraulic properties are often based on idealizations (e.g., statistical representations for apertures, fracture trace lengths, orientations, density) that can be fit to hydrologic or tracer results for aquifers with sufficiently large averaging scales (Hendricks-Franssen and Gomez-Hernandez 2002; Darcel et al. 2003; Wellman and Poeter 2006; Wellman et al. 2009; Xu and Dowd 2010; Sandve et al. 2014). However, such idealizations do not capture hydraulic properties of fractured aquifers at HRFS for many applications (e.g., in situ remediation). Detailed investigations at fracturedrock research sites (e.g., Grimsel, Aspö) have provided exceptional access to 3D rock exposures supplemented by coreholes and extensive hydrologic, tracer, and geophysical tests (e.g., Martinez-Landa and Carrera 2005, 2006; Mettier et al. 2006; Gustafson et al. 2009 and papers cited within; Soler et al. 2015). Yet, this information has not led to generally accepted methods for estimating fracture distributions to predict hydraulic and transport behavior.

One approach for quantitatively imaging a 3D aquifer volume is hydraulic tomography (HT), for which numerical, lab, and field studies have been conducted in $2 \mathrm{D}$ and 3D at a variety of scales (reviews in Cardiff and Barrash 2011 and Illman 2014). HT involves conducting multiple hydraulic tests in an aquifer volume, monitoring drawdown during the tests at many locations and depths, and using the data with inverse modeling to estimate the distribution of hydraulic properties (e.g., $K, S_{\mathrm{s}}$ ). Recently, Hochstetler et al. (2016) used HT to investigate a highly heterogeneous ( $K$ range of $10^{-7}$ to $10^{-1} \mathrm{~m} / \mathrm{s}$ ) unconsolidated sedimentary aquifer at HRFS with highquality results. For HT in fractured aquifers, synthetic and field studies using drawdown, tracer, and temperature data have been conducted in 2D (e.g., Hao et al. 2008; Klepikova et al. 2014; Trottier et al. 2014; Wang et al. 2016; Somogyvári et al. 2017; Fischer et al. 2018), and 3D (e.g., Klepikova et al. 2013) but we are only aware of distributed-parameter 3D HT field studies at the Mizunami research site in Japan (Illman et al. 2009; Zha et al. 2015). The Mizunami studies were at the scale of $>0.5 \mathrm{~km}$ lateral and vertical extent, or considerably larger than the HRFS focus of this paper and in situ remediation.

In this paper, we present the first demonstration of HT in a fractured-rock aquifer at HRFS to: (1) estimate the 3D $K$ distribution at high resolution (i.e., $K$ blocks $<1 \mathrm{~m}^{3}$ ) using no strict assumptions about the $K$ distribution or the statistics of fracture occurrence, (2) identify the 3D fracture network within the $K$ distribution, and (3) trace connectivity routes through the network. Here, tracing connectivity refers to identifying the routing of drawdown and flow through the 3D fracture network, and can be different for different forcing conditions (i.e., "dynamic connectivity" as classified by Renard and Allard [2013]).

\section{Field Site and HT Testing}

\section{NAWC Field Site}

HT testing occurred in July 2015 and August 2016 at the 83-89 research wellfield at the former Naval Air Warfare Center (NAWC), West Trenton, New Jersey (Figure 1A and 1B). The aquifer at NAWC is contaminated, primarily with trichloroethene; an active pump-and-treat system achieves containment (Lacombe and Burton 2010). The wellfield lies in dipping $\left(\sim 15^{\circ}\right.$ to $25^{\circ}$ ), competent-to-fissile, mudstone beds of the faulted Lockatong formation of the Newark Basin (Lacombe and Burton 2010; Ellefsen et al. 2012). The NAWC site is representative of many fractured sedimentary rock types in having bedding-plane fractures of variable $K$ and extent (e.g., Tiedeman et al. 2010, 2018; Robinson et al. 2015) and high-angle fractures that cross the bedding and locally connect the more-extensive bedding-plane fractures (Figure 1C).

The 83-89 wellfield has seven wells, six in a 9$\mathrm{m}$ diameter circle around a central well (Figure 1B and 1D). All wells have $15-\mathrm{cm}$ casing from the surface through approximately $15 \mathrm{~m}$ of moderately to highly weathered bedrock, and then are continuously cored (10.5$\mathrm{cm}$ diameter) boreholes open to the formation to a depth of 30 to $35 \mathrm{~m}$ below land surface (BLS). This results in approximately 15 to $20 \mathrm{~m}$ of open interval in each well for placement of packers (aided by televiewer and caliper $\operatorname{logs}$ ) to isolate intervals for pumping tests and drawdown monitoring. Static water level is generally approximately $3 \mathrm{~m}$ BLS.

Acoustic televiewer (ATV) $\operatorname{logs}$ for six of the wells identify one or two 0.5 to $1.5 \mathrm{~m}$ thick intervals of highly fractured mudstones (Figure 1D); this stratigraphic interval is referred to as the highly fractured zone (HFZ). The top part of the HFZ (light gray plane in Figure 1D) is at the location of a prominent high- $K$ black fissile mudstone bed recognized sitewide at NAWC (Tiedeman et al. 2010, 2018; Goode et al. 2014). However, lithologic logs show that, at elevations < approximately 24 masl, many individual beds are not continuous across the wellfield (Figure 2 of Shapiro et al. 2017), suggesting variability in sediment composition during deposition or postdeposition alteration of the lithology. Generally, densely distributed fractures occur above the HFZ, and sparse fracturing occurs below (Figure 1D).

\section{Hydraulic Testing and Drawdown Monitoring}

We used three packer configurations (Shallow, Middle, and Deep) to conduct HT pumping tests and monitor 


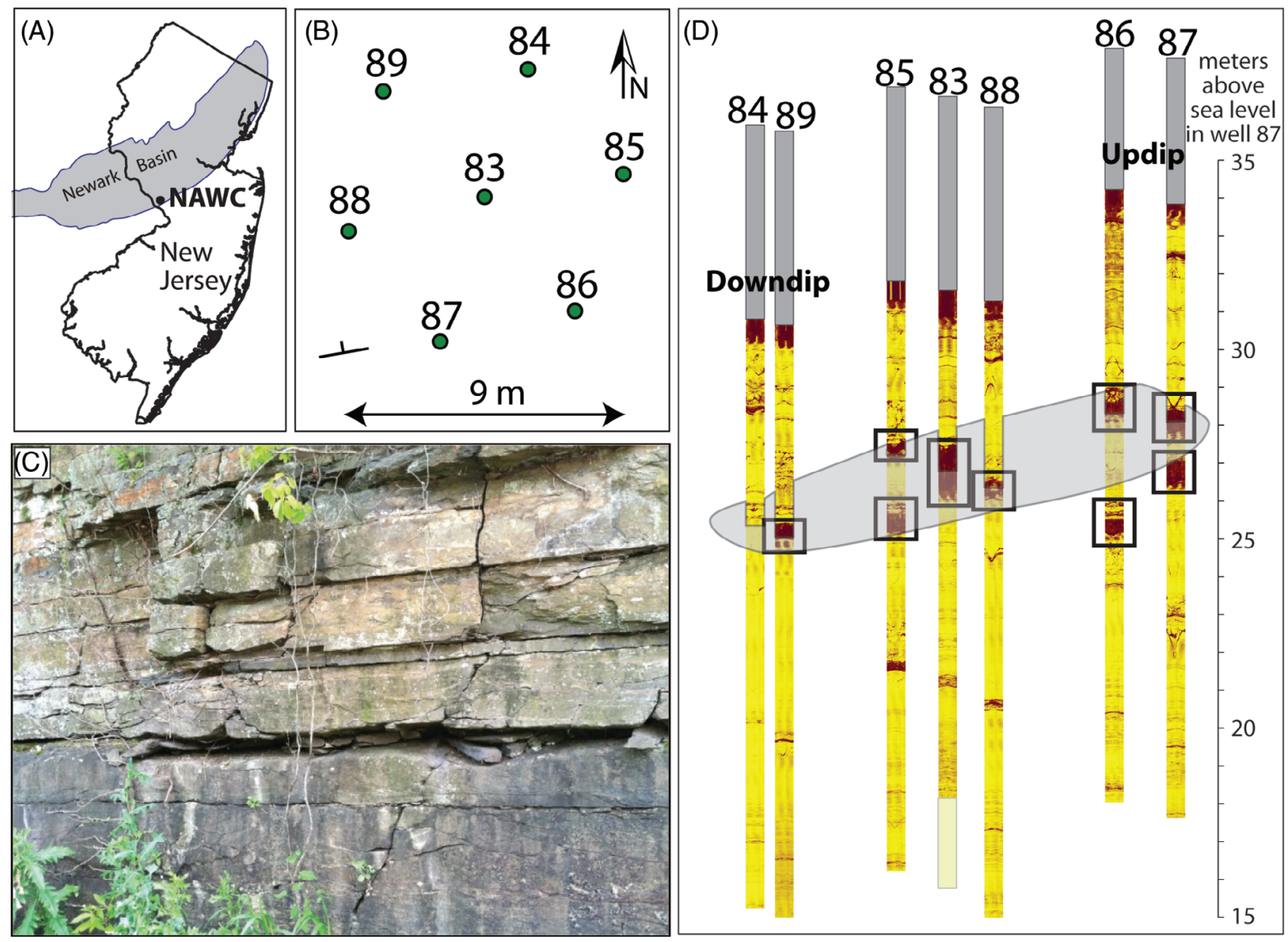

Figure 1. Former Naval Air Warfare Center (NAWC) field site for HT testing. (A) Location map of NAWC site. (B) Plan view of wellfield used for HT testing showing strike and dip of strata. (C) Outcrop of Lockatong Formation mudstones near NAWC showing bedding-plane and high-angle fractures. (D) ATV logs showing fractures (maroon bands) that intersect the boreholes. The highly fractured sequence of mudstones at approximately 24 to 28 masl, with borehole expressions outlined in black, is the HFZ. Light gray dipping plane connects the uppermost expression of the HFZ in each well. Gray borehole intervals above ATV logs represent well casings, which do not extend to land surface in this figure. Lateral distances between wells in dip direction are exaggerated.

drawdown in discrete intervals of the boreholes (Table 1, Figure 2). In each configuration, the packers were placed at a range of depths in the wells to achieve good coverage of isolated intervals over the portion of the wellfield targeted by that configuration. Collectively, the three configurations provided good coverage over all depths spanned by the well open intervals. Each configuration had 30 to 38 packer-isolated intervals. Additional details on the packer configurations are given in Appendix S1, Table S2, and Figure S2.

Forty-eight pumping tests were conducted in different packed-off intervals with pumping rates ranging from $30 \mathrm{~mL} / \mathrm{min}$ to $6.9 \mathrm{~L} / \mathrm{min}$ (Table 1 ). Test durations were mostly $45 \mathrm{~min}$ in 2015 and $60 \mathrm{~min}$ in 2016, with recovery time approximately twice the pumping time. Pumping rates were variable for numerous tests where rates changed as head declined in the pumped interval, or were reduced to maintain flow. Rates were measured periodically by a manual method and continuously with an inline flowmeter. The flowmeter data were less reliable for very early times (first 10 to $30 \mathrm{~s}$ ) and for tests with very low rates. Drawdown in most intervals was measured with fiber-optic (FO) transducers (FISO brand, model FOP-MIV-NS-369E (FISO Technologies, QC, Canada); resolution $<0.5$ to $1 \mathrm{~mm}$ water-see Hochstetler et al. 2016, Figure 2); some intervals were measured with strain-gauge (SG) transducers (GE Druck model PDCR 35D-10PSIG or PMC Engineering LLC model MTM 3211-15PSIG (PMC Engineering LLC, Danbury, CT); resolution approximately 0.5 to $1 \mathrm{~cm}$ water). Contaminated groundwater pumped during HT testing was collected in a portable tank and then pumped to the site water treatment system. Additional details on pumping tests and drawdown monitoring are given in Appendix S1. Field data collected during the HT tests are available from Tiedeman et al. (2019).

\section{Illustrative Examples of Heterogeneity}

We present two examples of HT test drawdown behavior that illustrate important types of $K$ heterogeneity, 


\begin{tabular}{|c|c|c|c|c|c|c|c|c|c|c|c|}
\hline \multirow[b]{2}{*}{$\begin{array}{l}\text { Test } \\
\text { Number }\end{array}$} & \multirow[b]{2}{*}{ Date } & \multirow{2}{*}{$\begin{array}{c}\text { Pumped } \\
\text { Well } \\
\text { Interval }\end{array}$} & \multirow{2}{*}{$\begin{array}{l}\text { Packer } \\
\text { Config }\end{array}$} & \multirow[b]{2}{*}{$\begin{array}{l}\text { Pump } \\
\text { Type }\end{array}$} & \multirow{2}{*}{$\begin{array}{c}\text { Pumping } \\
\text { Duration } \\
\text { (min) }\end{array}$} & \multirow{2}{*}{$\begin{array}{c}\text { Recovery } \\
\text { Duration } \\
\text { (min) }\end{array}$} & \multicolumn{3}{|c|}{$\begin{array}{l}\text { Pumping Rate } \\
\text { Measured Manually }\end{array}$} & \multirow[b]{2}{*}{$\begin{array}{l}\text { Use of } \\
\text { Test }\end{array}$} & \multirow{2}{*}{$\begin{array}{c}\text { Number of } \\
\text { Stress } \\
\text { Periods } \\
\text { in Model }\end{array}$} \\
\hline & & & & & & & $\begin{array}{l}\text { Range } \\
(\mathrm{L} / \mathrm{min})\end{array}$ & $\begin{array}{l}\text { Average } \\
(\mathrm{L} / \mathrm{min})\end{array}$ & Count & & \\
\hline 1 & July 16, 2015 & $85-\mathrm{I}$ & $\mathrm{S}$ & $\mathrm{s}$ & 52 & 93 & 5.8 to 6.0 & 5.9 & 4 & $\mathrm{i}$ & 2 \\
\hline 2 & July 16, 2015 & $85-\mathrm{H}$ & $\mathrm{S}$ & $\mathrm{s}$ & 45 & 105 & 5.7 to 5.9 & 5.8 & 4 & $\mathrm{i}$ & 2 \\
\hline 3 & July 16, 2015 & 87-I & $\mathrm{S}$ & $\mathrm{s}$ & 60 & Overnight & 4.7 to 5.0 & 4.8 & 6 & i & 2 \\
\hline 4 & July 17,2015 & $87-\mathrm{H}$ & $\mathrm{S}$ & $\mathrm{s}$ & 45 & 110 & 4.3 to 4.6 & 4.5 & 8 & $\mathrm{i}$ & 2 \\
\hline 5 & July 17, 2015 & $83-\mathrm{E}$ & S & s & 45 & 125 & 4.7 to 4.8 & 4.7 & 6 & $\mathrm{qc}$ & 3 \\
\hline 6 & July 17, 2015 & $89-\mathrm{K}$ & $\mathrm{S}$ & $\mathrm{s}$ & 30 & Overnight & 6.2 to 6.5 & 6.3 & 4 & $\mathrm{i}$ & 4 \\
\hline 7 & July 18,2015 & $86-\mathrm{M}$ & S & s & 45 & 303 & 5.1 to 5.4 & 5.3 & 6 & $\mathrm{i}$ & 2 \\
\hline 8 & July 18,2015 & $86-\mathrm{O}$ & $\mathrm{S}$ & $\mathrm{s}$ & 47 & Overnight & 6.0 to 6.4 & 6.2 & 5 & $\mathrm{qc}$ & 2 \\
\hline 9 & July 20, 2015 & $83-\mathrm{G}$ & $\mathrm{S}$ & $\mathrm{p}$ & 45 & 115 & 0.31 to 0.36 & 0.33 & 12 & $\mathrm{i}$ & 2 \\
\hline 10 & July 20,2015 & $83-\mathrm{F}$ & S & $\mathrm{p}$ & 45 & 118 & 0.31 to 0.33 & 0.33 & 10 & $\mathrm{i}$ & 4 \\
\hline 11 & July 20, 2015 & $85-\mathrm{J}$ & S & $\mathrm{p}$ & 47 & Overnight & 0.32 to 0.33 & 0.33 & 8 & $\mathrm{i}$ & 4 \\
\hline 12 & July 21, 2015 & $85-\mathrm{F}$ & $\mathrm{S}$ & $\mathrm{p}$ & 45 & 95 & 0.28 to 0.39 & 0.34 & 18 & i & 5 \\
\hline 13 & July 21, 2015 & $87-\mathrm{G}$ & $\mathrm{S}$ & $\mathrm{p}$ & 45 & 110 & 0.37 to 0.39 & 0.38 & 9 & $\mathrm{i}$ & 4 \\
\hline 14 & July 21, 2015 & 87-J & S & $\mathrm{p}$ & 45 & 115 & 0.32 to 0.34 & 0.34 & 10 & $\mathrm{i}$ & 4 \\
\hline 15 & July 21, 2015 & $88-\mathrm{I}$ & S & s & 45 & Overnight & 1.6 to 1.8 & 1.7 & 15 & $\mathrm{i}$ & 3 \\
\hline 16 & July 22, 2015 & $88-\mathrm{H}$ & $\mathrm{S}$ & $\mathrm{s}$ & 45 & 95 & 1.0 to 1.2 & 1.0 & 22 & $\mathrm{i}$ & 4 \\
\hline 17 & July 22, 2015 & $88-\mathrm{F}$ & $\mathrm{S}$ & $\mathrm{p}$ & 45 & 110 & 0.20 to 0.48 & 0.37 & 20 & $\mathrm{i}$ & 5 \\
\hline 18 & July 22,2015 & $83-\mathrm{H}$ & S & s & 45 & Overnight & 6.4 to 6.6 & 6.5 & 9 & $\mathrm{i}$ & 2 \\
\hline 19 & August 6, 2016 & $85-\mathrm{I} 3$ & D & $\mathrm{s}$ & 61 & 150 & 6.5 to 7.1 & 6.8 & 8 & $\mathrm{i}$ & 3 \\
\hline 20 & August 6, 2016 & $89-\mathrm{H} 2$ & D & $\mathrm{s}$ & 60 & Overnight & 6.0 to 7.3 & 6.8 & 9 & i & 3 \\
\hline 21 & August 8, 2016 & $85-J 5$ & $\mathrm{D}$ & $\mathrm{p}$ & 60 & 210 & 0.64 to 1.4 & 0.80 & 19 & $\mathrm{i}$ & 4 \\
\hline 22 & August 8, 2016 & 83-I3 & $\mathrm{D}$ & $\mathrm{p}$ & 60 & Overnight & 0.43 to 0.98 & 0.61 & 20 & $\mathrm{i}$ & 5 \\
\hline 23 & August 9, 2016 & 88-J5 & D & $\mathrm{p}$ & 22 & 153 & 0.24 to 1.2 & 0.76 & 10 & $\mathrm{i}$ & 4 \\
\hline 24 & August 9, 2016 & 88-I3 & $\mathrm{D}$ & $\mathrm{p}$ & 29 & 226 & 1.2 to 1.2 & 1.2 & 14 & $\mathrm{i}$ & 2 \\
\hline 25 & August 9, 2016 & 87-J5 & $\mathrm{D}$ & $\mathrm{p}$ & 37 & Overnight & 0.17 to 0.49 & 0.43 & 18 & $\mathrm{i}$ & 3 \\
\hline 26 & August 10, 2016 & 89-J2 & $\mathrm{D}$ & $\mathrm{p}$ & 30 & 73 & 0.30 to 0.62 & 0.46 & 14 & $\mathrm{i}$ & 4 \\
\hline 27 & August 10, 2016 & 83-J4 & D & $\mathrm{p}$ & 60 & 132 & 0.04 to 0.05 & 0.04 & 16 & $\mathrm{qc}$ & 3 \\
\hline 28 & August 10, 2016 & 84-J1 & $\mathrm{D}$ & $\mathrm{p}$ & 13 & Overnight & 0.02 & 0.02 & 1 & $\mathrm{i}$ & 2 \\
\hline 29 & August 11, 2016 & 87-J7 & $\mathrm{D}$ & $\mathrm{p}$ & 60 & 312 & 0.09 to 0.12 & 0.11 & 16 & $\mathrm{i}$ & 4 \\
\hline 30 & August 11, 2016 & $85-\mathrm{J} 4$ & $\mathrm{D}$ & $\mathrm{p}$ & 60 & Overnight & 0.04 to 0.08 & 0.07 & 16 & $\mathrm{i}$ & 3 \\
\hline 31 & August 16, 2016 & 88-J3 & $\mathrm{M}^{1}$ & $\mathrm{p}$ & 16 & 69 & 0.12 to 0.22 & 0.17 & 5 & $\mathrm{i}$ & 1 \\
\hline 32 & August 16, 2016 & 84-H & $\mathrm{M}^{1}$ & $\mathrm{p}$ & 34 & Overnight & 0.41 to 0.43 & 0.42 & 16 & $\mathrm{qc}$ & 2 \\
\hline 33 & August 17, 2016 & $88-\mathrm{H} 2$ & M & $\mathrm{p}$ & 33 & 117 & 0.11 to 0.13 & 0.12 & 16 & $\mathrm{n}$ & 4 \\
\hline 34 & August 17, 2016 & $85-\mathrm{I} 2$ & M & $\mathrm{s}$ & 60 & Overnight & 5.8 to 6.0 & 5.9 & 18 & $\mathrm{i}$ & 2 \\
\hline 35 & August 18, 2016 & $83-\mathrm{F} 2$ & M & $\mathrm{p}$ & 60 & 119 & 0.75 to 1.5 & 0.97 & 36 & i & 4 \\
\hline 36 & August 18, 2016 & $88-G 2$ & M & $\mathrm{p}$ & 60 & 140 & 0.26 to 0.48 & 0.36 & 30 & $\mathrm{qc}$ & 4 \\
\hline 37 & August 18, 2016 & 87-G2 & M & $\mathrm{p}$ & 60 & Overnight & 0.33 to 0.74 & 0.41 & 29 & $\mathrm{i}$ & 5 \\
\hline 38 & August 19, 2016 & $88-E F$ & M & $\mathrm{p}$ & 60 & 120 & 0.33 to 1.9 & 1.1 & 30 & $\mathrm{i}$ & 5 \\
\hline 39 & August 19, 2016 & 87-EF & M & $\mathrm{p}$ & 60 & 150 & 1.8 to 1.9 & 1.9 & 25 & $\mathrm{i}$ & 1 \\
\hline 40 & August 19, 2016 & $85-E F$ & M & $\mathrm{p}$ & 60 & Overnight & 1.5 to 1.5 & 1.5 & 29 & $\mathrm{i}$ & 3 \\
\hline 41 & August 20, 2016 & 89-H & M & s & 60 & 208 & 6.5 to 6.9 & 6.8 & 15 & $\mathrm{i}$ & 1 \\
\hline 42 & August 20, 2016 & $87-\mathrm{I} 2$ & M & s & 60 & Overnight & 5.3 to 5.6 & 5.5 & 7 & $\mathrm{i}$ & 1 \\
\hline 43 & August 22, 2016 & $85-\mathrm{J} 2$ & $\mathrm{M}$ & $\mathrm{p}$ & 60 & 125 & 0.19 to 0.23 & 0.21 & 29 & $\mathrm{i}$ & 2 \\
\hline 44 & August 22, 2016 & $84-\mathrm{F}$ & M & $\mathrm{p}$ & 60 & 115 & 0.10 to 0.12 & 0.11 & 20 & $\mathrm{i}$ & 1 \\
\hline 45 & August 22, 2016 & $83-G 2$ & $\mathrm{M}$ & $\mathrm{p}$ & 60 & Overnight & 1.1 to 1.2 & 1.2 & 30 & $\mathrm{i}$ & 2 \\
\hline 46 & August 23, 2016 & 84-E & M & $\mathrm{p}$ & 60 & 130 & 0.86 to 1.9 & 1.4 & 30 & $\mathrm{i}$ & 6 \\
\hline 47 & August 23, 2016 & 88-I2 & M & s & 60 & 115 & 1.7 to 2.0 & 1.9 & 30 & $\mathrm{i}$ & 2 \\
\hline 48 & August 23, 2016 & $83-\mathrm{H} 2$ & M & $\mathrm{s}$ & 60 & Overnight & 6.7 to 7.1 & 6.9 & 18 & $\mathrm{i}$ & 2 \\
\hline
\end{tabular}

S, Shallow; D, Deep; M, Middle; s, submersible; p, peristaltic; i, inversion; qc, quality check; n, not used.

Notes: Configurations S, D, and $\mathrm{M}$ are shown in Figures 2 and S2 and Table S2.

${ }^{1}$ Well 86 had Deep configuration for these tests. 


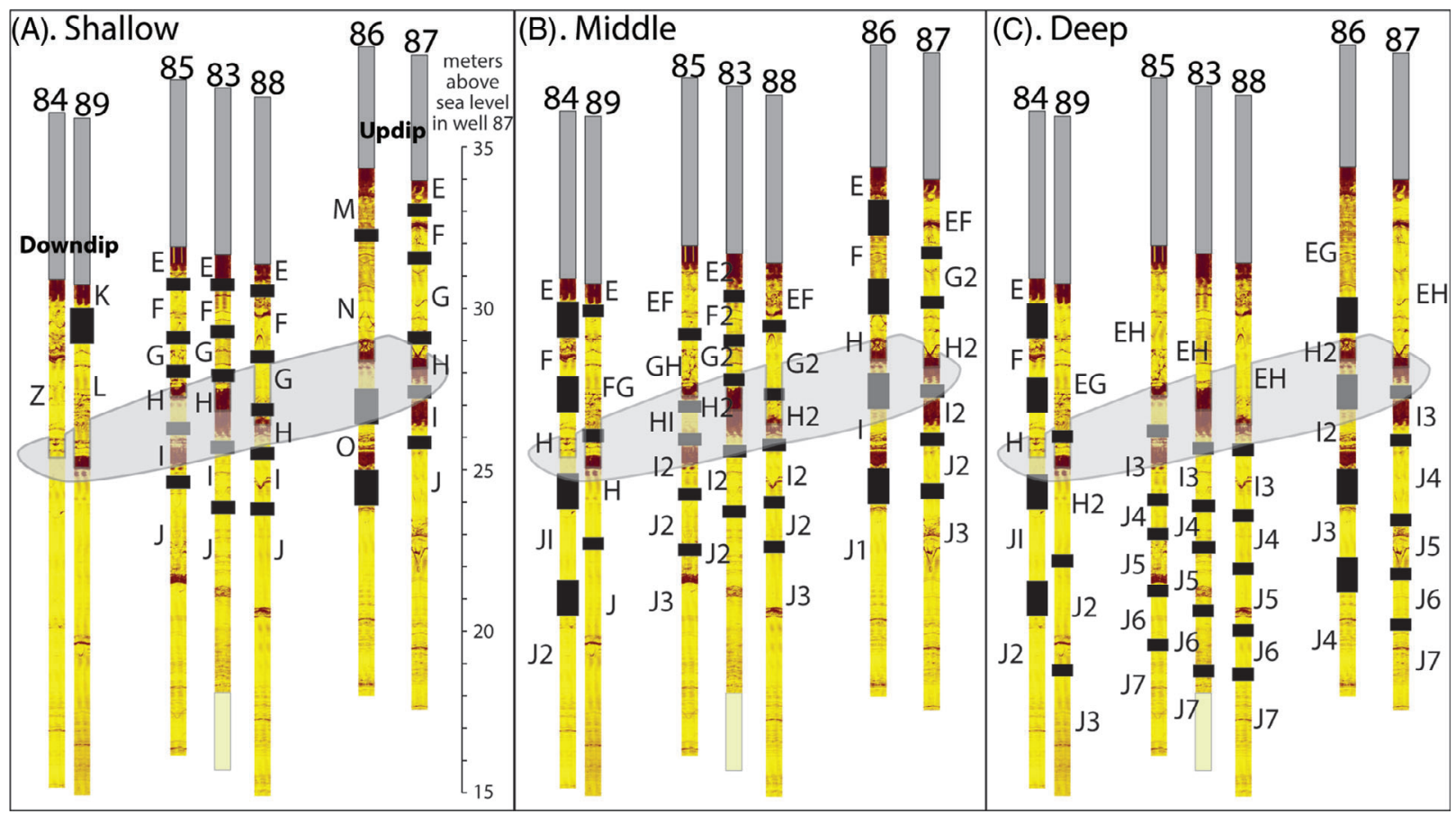

Figure 2. (A) Shallow, (B) Middle, and (C) Deep packer configurations used during different phases of HT testing at NAWC. Black rectangles placed on the ATV logs represent packers, and labels identify names of the packer-isolated intervals (e.g., label "E" on well 83 is interval named 83-E). Drawdown was monitored in all labeled intervals; pumping tests were conducted in a subset of the intervals (see Table 1).

and that require 3D HT modeling to be explained: (1) heterogeneity associated with dominant bedding-plane fractures and (2) across-bedding heterogeneity through the 3D fracture network. Site-specific results are not used to show what occurs locally in this aquifer as such, but rather are used to demonstrate the capabilities of 3D HT for identifying and characterizing important heterogeneity features of fractured rocks.

\section{Field Data Example of Heterogeneity Associated with Dominant Bedding-Plane Fractures}

In fractured rocks, flow often occurs dominantly in one or a few fractures or fracture zones (NAS 2015). This occurs at NAWC, where high- $K$ bedding-plane fractures are associated with discrete fissile or laminated mudstone beds (Tiedeman et al. 2010, 2018). Based on strong fracturing expression in the ATV and caliper logs for six of the wells (all except 84) at the location of the sitewide high- $K$ fissile mudstone (Figures 1D and S2), one might expect these six wells to be hydraulically connected within the HFZ (see also Le Borgne et al. 2007).

However, when wells 83,85 , and 87 were each pumped at similar rates $(4.4$ to $6.6 \mathrm{~L} / \mathrm{min})$, in turn, from intervals open to the HFZ in the Shallow configuration $(83-\mathrm{H}, 85-\mathrm{H}, 87-\mathrm{H}$; Figures $3 \mathrm{~A}$ and $\mathrm{S} 2$; Table 1), the following different types of drawdown behavior were observed in HFZ intervals at nonpumped wells (Figure 3B): (1) short lag to drawdown initiation and significant drawdown $(0.2$ to $0.6 \mathrm{~m}$ at end of test) at wells $83,85,86$, and 87 ; but (2) long lag and weak to modest drawdown ( 0.02 to $0.08 \mathrm{~m}$ at end of test) in wells 88 and 89, and also in well 84 (open borehole in Shallow configuration) with minor fracture expression at the HFZ position.

Pumping from intervals of 84,88 , and 89 open to the HFZ (intervals $\mathrm{H}$ and $\mathrm{H} 2$ in Table 1 and Figures 2 and S2) reveals additional heterogeneity. A pumping rate could be achieved at $89(6.8 \mathrm{~L} / \mathrm{min})$ similar to that at wells 83,85 , and 87 , suggesting that $K$ is high at the HFZ interval of 89 despite its small drawdown response to tests in 83,85 , and 87 . However, only significantly lower pumping rates $(\leq 1 \mathrm{~L} / \mathrm{min})$ could be achieved from 84 and 88 , suggesting that $K$ is lower at the HFZ interval of these wells. Such highly variable drawdown behaviors are not unexpected in a fractured aquifer, but HT modeling is needed to estimate the heterogeneous 3D $K$ distribution that reveals the lateral and vertical extents, and internal variations, of principal hydrogeological features that are consistent with these behaviors.

\section{Field Data Example of Across-Bedding Heterogeneity}

In response to pumping from the HFZ at well interval 83-H, observation intervals in well 88 (Figure 4A) have (1) lag times to initial drawdown and (2) drawdown magnitudes that are distinctly "out of sequence" with respect to vertical or stratigraphic position relative to the pumped interval. The order in which the intervals of 88 respond is: $88-\mathrm{I}, 88-\mathrm{F}, 88-\mathrm{E}$ and $88-\mathrm{J}, 88-\mathrm{G}, 88-$ $\mathrm{H}$ (Figure 4B). Note that $88-\mathrm{H}$ has the strong fracturing expression of the HFZ and is along strike and at a similar elevation as the $83-\mathrm{H}$ pumping interval, but $88-\mathrm{H}$ is the last zone to respond to pumping and has the second-to-last 


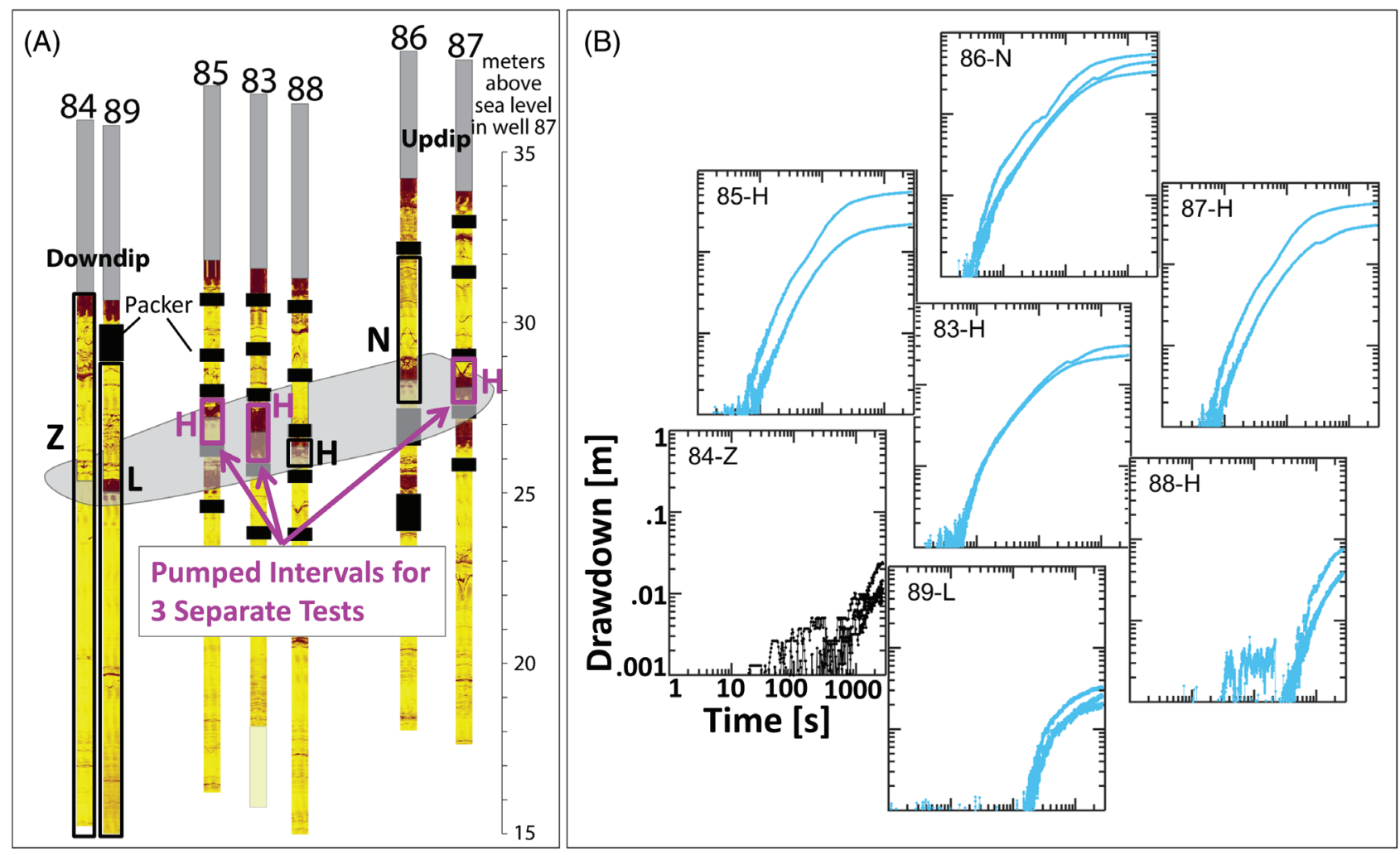

Figure 3. Drawdown data illustrating heterogeneity within bedding. (A) 3D perspective diagram of wellfield with ATV logs, packed-off intervals in the Shallow configuration open to the HFZ (outlined by pink and black rectangles), and light gray plane representing dip of the HFZ. (B) Drawdown vs. time in intervals open to the HFZ for three tests with pumping from the HFZ (83-H, 85-H, 87-H-pink intervals in A). Curves for all three tests are shown in the panels for wells 84, 86, 88, and 89 , but only two curves are displayed in the panels for wells 83,85 , and 87 because drawdown in the pumped interval is not shown. Drawdown and time axes are identical on all panels of $B$.

amount of total drawdown. Such heterogeneous behavior is not unexpected in a fractured aquifer, but HT modeling is needed to identify the 3D fracture network, and the migration of drawdown and flow through it, to explain this behavior.

\section{Modeling Methods}

\section{Forward Modeling}

We used an equivalent porous medium (EPM) modeling approach for forward simulations of the pumping tests, with a 3D heterogeneous distribution of $K$ representing the rock matrix and fractures. Heterogeneous EPM modeling has been applied in many fractured aquifer studies (e.g., Reeves et al. 2008; Tiedeman et al. 2010, 2018; Chapman et al. 2013; Zha et al. 2015; Wang et al. 2016). Discrete fracture network modeling (DFN) is an alternative approach to simulate the flow in fractured systems. While aspects of DFN modeling have appeal, such as the ability to incorporate fractures with realistic apertures, such modeling requires assumptions about fracture properties and locations that we cannot support with available data. That is, we accept the reduced resolution of individual fractures in EPM modeling to avoid making assumptions in DFN modeling that likely would bias the estimated $K$ field for the scale of this study. We acknowledge that the usage of the term "fracture" in this paper is inexact due to the EPM modeling approach, but we use it without additional modifiers (such as "EPM fracture") for simplicity in presentation.

Each pumping test is represented by a separate MODFLOW (Harbaugh 2005) model that simulates water-level changes caused by pumping. Most model aspects are the same for all tests. Each model domain is $200 \mathrm{~m}$ by $200 \mathrm{~m}$ laterally and $38 \mathrm{~m}$ thick, with constanthead boundaries at the sides of the domain. $K$ is spatially variable in a $21 \mathrm{~m}$ by $21 \mathrm{~m}$ (lateral) by $26 \mathrm{~m}$ (thick) estimation volume centered on the wellfield, with buffer zones of constant $K=10^{-5} \mathrm{~m} / \mathrm{s}$ above and to the sides, and $K=10^{-8} \mathrm{~m} / \mathrm{s}$ below (Figure S3).

We represent $S_{\mathrm{s}}$ with the spatially uniform value of $5 \times 10^{-6} \mathrm{~m}^{-1}$ based on previous modeling at NAWC (Tiedeman et al. 2010). While it is well established that $S_{\text {S }}$ is heterogeneous within fractured rocks (e.g., Rutqvist and Stephansson 2003; Quinn et al. 2016) and even within a single fracture (e.g., Castagna et al. 2011), treating $S_{\text {s }}$ as uniform has not significantly degraded 3D $K$ estimates in previous HT studies in heterogeneous sediments and field and synthetic fractured aquifers (Hao et al. 2008; Cardiff and Barrash 2011; Castagna et al. 2011; Cardiff et al. 2013; Hochstetler et al. 2016). 


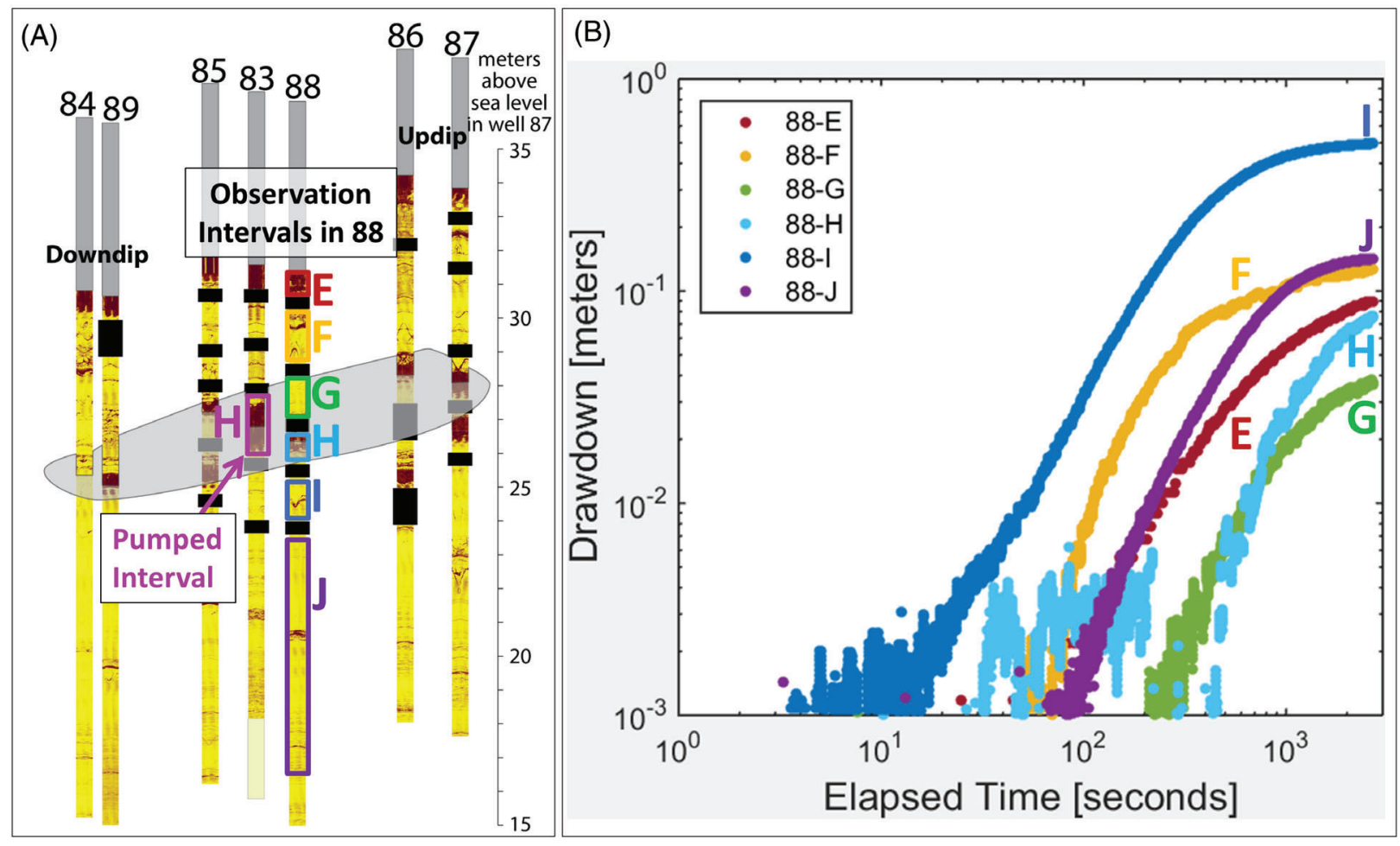

Figure 4. Example of across-bedding heterogeneous behavior during test 83-H. (A) Packed-off intervals of well 88 are colorcoded to match drawdown curves in B. (B) Across-bedding heterogeneity is evident by highly variable drawdown response times and magnitudes in intervals of well 88 that do not systematically decrease with increasing vertical distance of the intervals from the 83-H pumped interval in the HFZ.

The seven wells are represented explicitly. Model cells occupied by open intervals are assigned $K=10^{-2} \mathrm{~m} / \mathrm{s}$. Cells that represent packers are assigned $K=10^{-12} \mathrm{~m} / \mathrm{s}$. This value is at the low end of the estimated $K$ distribution (only three $K$ blocks [see below for $K$ discretization] have values $<10^{-12} \mathrm{~m} / \mathrm{s}$ ) and enabled these cells to be barriers to flow. The location, rate, and duration of pumping for each model are specified based on the field pumping conditions for the test simulated. Pumping rates varied during most tests, particularly at early time (Table 1). The number of stress periods in the models ranged from one to five, to accommodate this variability.

Additional forward model details are provided in Appendix S2 and Figure S3, and archived models are available from Tiedeman and Barrash (2019).

\section{Inverse Modeling}

We used a Bayesian geostatistical approach (Kitanidis and Vomvoris 1983; Kitanidis 1995) for inversion to estimate 3D $K$, solved with a modified LevenbergMarquardt (L-M) method (Nowak and Cirpka 2004). The L-M method is needed for estimation of highly heterogeneous $K$ fields, with a high degree of head nonlinearity with respect to $K$. Uncertainty in the estimated 3D $K$ is calculated as the square roots (standard deviations) of the diagonals of the posterior covariance matrix. Our implementation of the inversion followed that of Hochstetler et al. (2016), which built on Cardiff et al. (2013), and is summarized in Appendix S2.
We estimated spatially distributed $K$, starting with uniform $K=10^{-5} \mathrm{~m} / \mathrm{s}$. The $21 \mathrm{~m} \times 21 \mathrm{~m} \times 26 \mathrm{~m}$ estimation volume was discretized into 22,932 $1 \mathrm{~m} \times 1 \mathrm{~m} \times 0.5 \mathrm{~m}$ blocks. Block dimensions are large relative to fracture apertures and hence include both fractures and rock matrix, so this approach cannot estimate exact fracture geometries. Instead, it estimates the volumes in which fractures occur. However, block dimensions are relatively small compared to the lengths of hydraulically important fractures at NAWC, and thus estimated regions of contiguous intermediate- to high-K blocks can capture key features of the fracture network (as shown in 2D by Hao et al. 2008), including approximate fracture locations, orientations, and hydraulic properties.

$S_{\mathrm{S}}$ is spatially uniform, as noted above, and is not estimated. While some HT studies in highly heterogeneous aquifers have inverted for spatially variable $S_{\mathrm{s}}$ with favorable results (e.g., Berg and Illman 2011; Castagna et al. 2011), achieving stable, realistic, high-resolution 3D HT estimations for both $S_{\mathrm{s}}$ and $K$ in heterogeneous systems remains a topic for further research. Additional discussion of inverting for $S_{\mathrm{s}}$, including general issues and exploratory inversions conducted in this study, is given in Appendix S2.

The inverse method uses geostatistical regularization, or prior information, implemented as a parameter covariance matrix with spatial correlation lengths of $4 \mathrm{~m}, 4 \mathrm{~m}$, and $2 \mathrm{~m}$ in, respectively, the $\mathrm{x}, \mathrm{y}$, and $\mathrm{z}$ directions and a variance of $\log _{10}(K)=4$. Due to the high density of 
drawdown observations in $3 \mathrm{D}$, the spatial variability of $K$ within the wellfield is driven largely by these data, and so the correlation lengths and variance impose weak constraints on the inversion (e.g., Liu et al. 2002).

Of the 48 field tests, 42 were used in the inversion (Table 1). One test was suspect and not used, and five tests were withheld for a post-inversion quality check. For the 42 tests used, one to five points were manually selected from the drawdown curve for each observation interval, to obtain data for matching simulated and observed behavior in the inversion. Points were generally spaced evenly in $\log _{10}$ (elapsed time) (see Figures 8 and S8). Manual selection allowed consideration of the wide variability in time to drawdown initiation, pumping rate changes, curve shape, drawdown magnitude, and quality of the responses. This yielded 4693 inversion observations from 1619 drawdown curves. Weights were defined using standard deviations of observation error of 0.0015 and $0.003 \mathrm{~m}$ for drawdowns measured by, respectively, FO and SG transducers. The smaller value for FO transducers accounts for their higher resolution and accuracy.

To solve the inversion, we used USGS highperformance computing (HPC) facilities to massively parallelize sensitivity calculations. This enabled the inversion to be completed in approximately 18 days of compute time instead of the approximately 140 days required using available desktop computers.

Additional details about the inverse modeling and data treatment are in Appendix S2.

\section{Results: Estimated 3D K Distribution, Fracture Network, and Connectivity}

Figure 5 presents the estimated 3D $K$ distribution, ranging from $10^{-13}$ to $0.1 \mathrm{~m} / \mathrm{s}$. For interpretation of the results, we first identify principal hydrogeologic features in the estimated 3D $K$ distribution, and show how such features explain heterogeneous HT test behavior such as that in prominent bedding-plane fractures in the HFZ (Figures 3 and 5). However, the connecting fractures between higher $K$ fractures and secondary fractures, and branching into lower $K$ regions, are not readily evident by examining the 3D $K$ distribution directly. This is due especially to the large range in $K$ making it difficult to see local, smaller contrasts in $K$ between fractures and surroundings, and to distinguish fractures having lessextensive dimensions due to the discretization (i.e., block size) of parameterization. So, at a finer scale of detail, we next identify the fracture network (within the 3D $K$ distribution), and connectivity through the network, using two approaches: (1) by tracing drawdown progression in a simulated HT test (using the illustrative example of "out of sequence" drawdown behavior across bedding, Figure 4) and (2) by tracking particles under induced gradients across the wellfield.

\section{Principal Hydrogeologic Features}

Within the 12 orders of magnitude $K$ range, important 3D features are recognized that have clear $K$ contrasts to their surroundings, but also have internal variation of $K$ to a lesser degree (Figure 5). Two types of higher$K$ features are: (1) the HFZ, which as described above consists locally of one or two fractures or fractured zones in a stratigraphic sequence of mudstone beds that dip about $15^{\circ}$ to $20^{\circ} \mathrm{NW}$ and (2) secondary fractures which extend along strike with limited lateral and vertical extent, and with internal variability in $K$. Two such fractures are shown in Figure $5 \mathrm{~B}$ to $5 \mathrm{D}$ as $\mathrm{X} 2$ and $\mathrm{X} 3$. Two types of lower- $K$ features are: (3) a low- $K$ zone that strikes about $\mathrm{N}^{\circ} 0^{\circ} \mathrm{E}$ and separates the HFZ into up-dip and down-dip segments (feature 2 on Figure 5); and (4) regions of very low- $K$ rock matrix surrounding fractures, including most of the investigated volume below the HFZ. These features are generally consistent with the expected $K$ heterogeneity for the dipping mudstones, with the caveat that we estimate the volumes in which fractures occur, as noted above, rather than exact fracture geometries.

\section{HFZ Drawdown Behavior Explained}

The $K$ distribution within the dipping HFZ (Figure 5) shows: (1) very high $K\left(\sim 0.1\right.$ to $\left.10^{-4} \mathrm{~m} / \mathrm{s}\right)$ up-dip at 83 , $85,86,87$, and down-dip at 89 ; (2) very low $K\left(\sim 10^{-10}\right.$ to $10^{-8} \mathrm{~m} / \mathrm{s}$ ) at 84 and 88 ; and (3) a $\mathrm{N} 60^{\circ}$ E-trending low$\mathrm{K}\left(\sim 10^{-10}\right.$ to $\left.10^{-7} \mathrm{~m} / \mathrm{s}\right)$ zone between 83 and 89 that is a barrier to connectivity between the up-dip and downdip high- $K$ portions of the HFZ (feature 2 on Figure 5). This estimated heterogeneity, with the separation of the HFZ into up-dip and down-dip segments across a low- $K$ zone, explains the drawdown behavior observed in well intervals intersecting the HFZ (Figure 3B). Well intervals in the up-dip segment of the HFZ (83-H, 85-H, 86-N, 87$\mathrm{H}$; Figure $3 \mathrm{~A}$ ) have similar rapid, strong (well-connected) drawdown responses, when any of these intervals is pumped, because of the very high $K$ throughout this segment. Wells 84 and 88 have delayed, lower drawdown responses because they are in a zone with $K$ that is orders of magnitude lower. Well 89 also has delayed responses because, although it is in the high-K down-dip segment of the HFZ, it is separated from the up-dip segment by the low-K zone that acts as a hydraulic barrier.

In keeping with the conceptual model of the HFZ as a heterogeneous 3D feature with varying thickness, locally varying $\mathrm{K}$, and spatially heterogeneous fracturing within the mudstone beds as shown by fracture expressions at the wells (Figures 1D and S2), we note that the HFZ in the estimated $K$ field has two distinct high- $K$ fractures at different elevations in well 85 (feature 3 in Figure 5D). At well 85, the Middle packer configuration allowed collection of separate drawdown observations from each of the two highly fractured beds intersecting the borehole, as well as from the intervening less-fractured rock. These data enabled the inversion to resolve vertical variation in $K$ and estimate two high- $K$ fractures within the HFZ separated by lower $K$ between them. Conversely, at well 86 where two distinct highly fractured beds are indicated in ATV logs, packer lengths did not allow any of the three configurations to have an isolated interval 

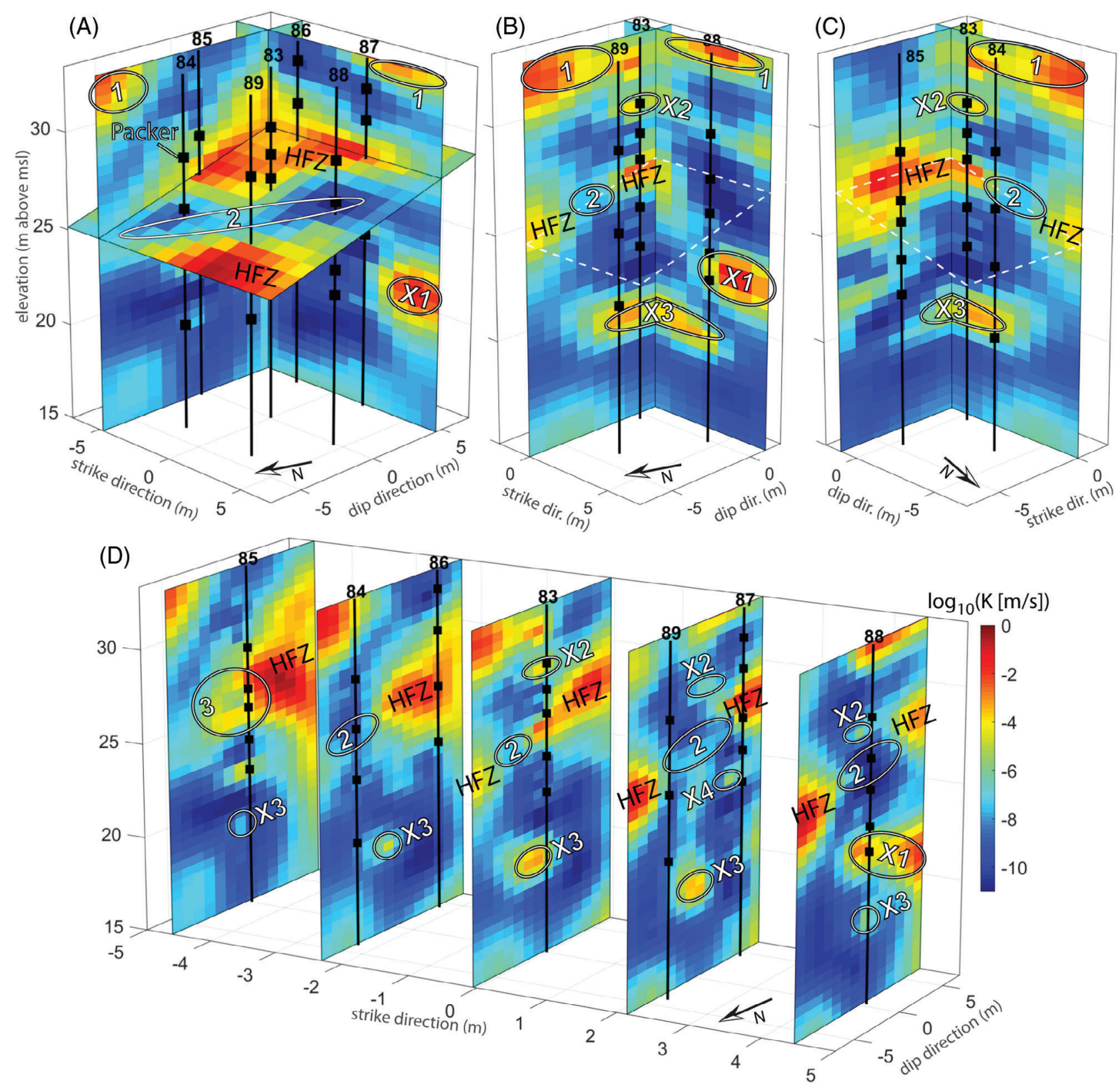

Figure 5. Slices through estimated $K$ distribution. Middle packer (black squares) configuration shown. Labeled features are: 1 - high $K$ in regolith; 2 -low- $K$ zone between up-dip and down-dip segments of the HFZ; 3 - two separate fractures in the HFZ near well 85; and secondary fractures X1, X2, X3, and X4 (see also Figures 7, S6, and S7). (A) View to the southeast, with strike-oriented vertical slice through wells 86 and 87 , dip-oriented vertical slice through well 85 , and inclined plane aligned with estimated dip of the HFZ. (B) View to the southeast, with dip-oriented vertical slice through well 83 and strike-oriented vertical slice $1 \mathrm{~m}$ south of well 83. Dipping plane in $(\mathrm{A})$ is outlined by white dashed line. (C) View to the southwest, with same slices as in (B) (eastward half of strike-oriented slice is now visible). (D) Dip-oriented slices along a "stretched" axis, showing lateral extent of features and $K$ variation along strike.

in the intervening less fractured rock (Figures 1D, 2 and $\mathrm{S} 2 \mathrm{~A})$. Hence the inversion was unable to separate the two highly fractured beds and the estimated HFZ is very thick at well 86.

The $\mathrm{N} 60^{\circ}$ E-trending low- $K$ zone is characterized in detail by HT (feature 2 in Figure 5) but was not recognized as a coherent low- $K$ zone from core, borehole logs, or tracer testing in combination with electrical resistivity tomography (ERT; Robinson et al. 2015; Shapiro et al. 2017). However, the geologic nature of this low- $K$ zone is unclear. We offer two working hypotheses: (1) the zone might be a local significant lateral heterogeneity within bedding planes of the HFZ and (2) because the estimated 3D $K$ distribution and hydrologic behavior allow that the low- $K$ zone could extend above and below the HFZ, it might be a narrow, approximately vertical, fault zone or zone of subsidiary accommodation structures related to nearby steeply dipping faults at NAWC (Lacombe and Burton 2010; Ellefsen et al. 2012). Further analysis of this question is beyond the scope of this study. 

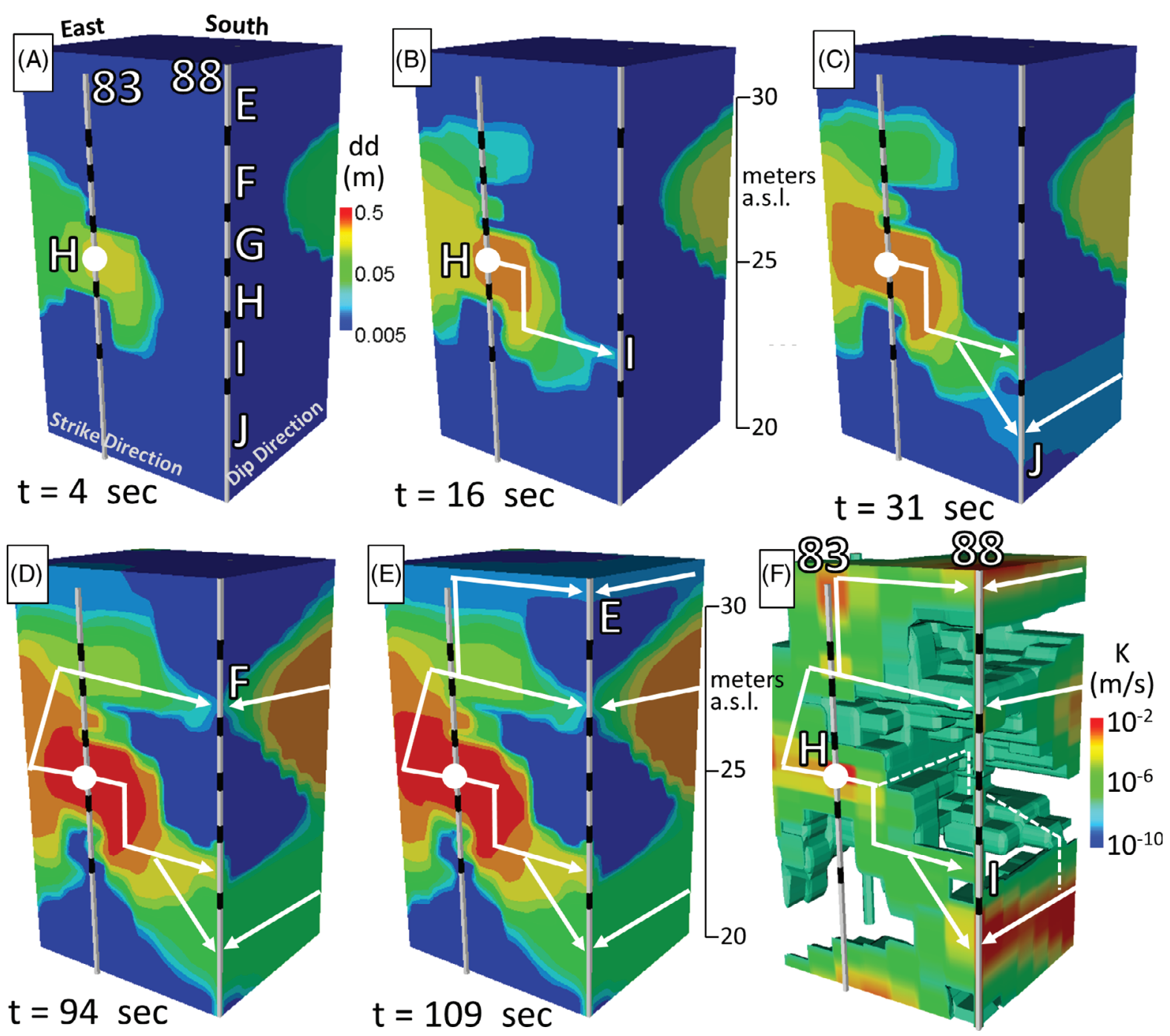

Figure 6. Network and connectivity visualization using simulated drawdown (dd) progression from pumping at interval 83-H to observation intervals in 88, and 3D $K$ distribution. Cropped view of 3D wellfield volume shows a strike-oriented plane through wells 83 and 88 and a dip-oriented plane through well 88. (A) At elapsed time $t=4 \mathrm{~s}$ since onset of pumping at 83-H (white circle), drawdown moves along strike and downward toward well 88, and has expanded through the HFZ south of 88. (B to E) Drawdown progressively reaches intervals I, J, F, and E of well 88 (see also Figures S6 to S7). (F) View of 3D $K$ distribution with thresholding to show only $K$ values $>5 \times 10^{-8} \mathrm{~m} / \mathrm{s}$.

\section{D Fracture Network and Connectivity Routes}

We use two approaches to locate the 3D fracture network and connectivity routes through it: tracing drawdown and particle tracking. Both approaches use flow simulations with the estimated $3 \mathrm{D} K$ distribution. The term "connectivity" here means drawdown or flow routes through the 3D fracture network caused by forcing, such as pumping from a particular location (Renard and Allard 2013). The 3D $K$ distribution and the fracture network within it do not change for different drawdown or particle tracking simulations, but connectivity is dynamic, in that it changes as a function of the pumping or other system forcings.

\section{Drawdown Tracing to Locate the Fracture Network and Connectivity Routes}

Because drawdown propagation and corresponding flow during pumping tests will dominantly follow connected pathways that are relatively high- $K$ (i.e., relatively high diffusivity, where $S_{\mathrm{s}}$ is constant in the modeling, as noted previously) compared with surrounding low- $K$ unfractured mudstone, we can locate the fracture network and connectivity through it by tracing drawdown in simulated HT tests. We demonstrate this approach by following, or tracing, simulated drawdown through the fracture network from pumped interval 83-H (in the up-dip segment of the HFZ) to observation intervals in well 88 (Figure 6). This simulation explains the heterogeneous, across-bedding, field behavior noted above where response times and drawdown magnitudes in intervals of well 88 do not systematically decrease with increasing vertical distance from the pumped interval in the HFZ (Figure 4B).

To identify the connectivity routes followed by the drawdown, and relate them to the 3D fracture network, we view a time series of drawdown through two planes 
(A)

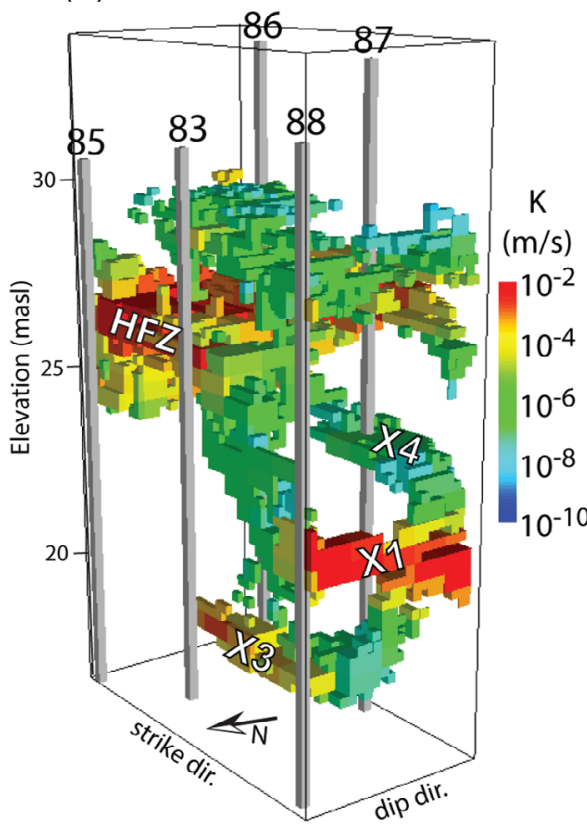

(B)

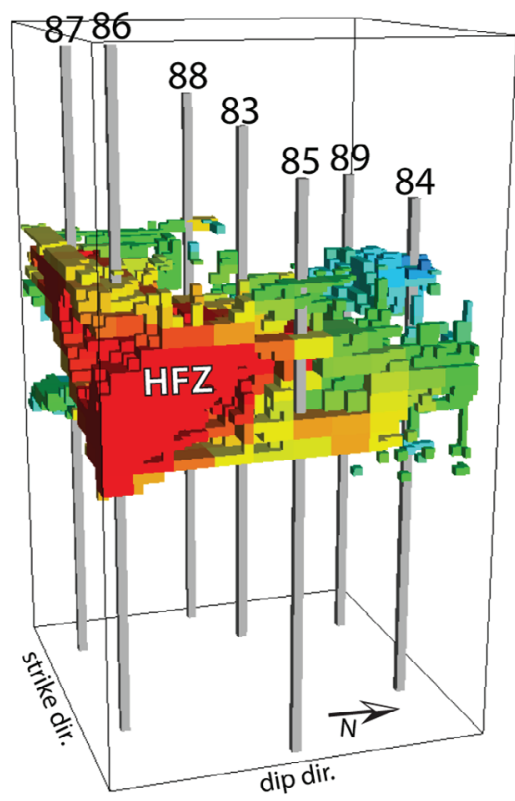

(C)

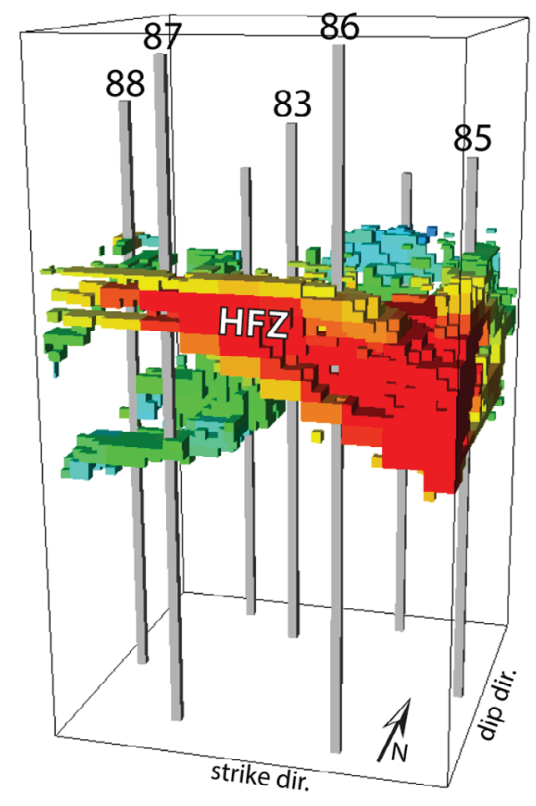

Figure 7. MODFLOW model cells with fast channelized pathways, obtained by postprocessing particle tracking results. Cells are colored according to their estimated $K$ values. (A) Investigated volume is cropped to only show cells south of wells 83, 85, and 88 at elevations of approximately 18 to 30 masl, which identify a fracture network near wells 83 , 87, and 88 . Fractures $\mathrm{X1}, \mathrm{X3}$, and $\mathrm{X} 4$ are also shown in Figure 5. (B and $\mathrm{C}$ ) Investigated volume is cropped to only show cells at approximate elevation of the HFZ ( 24 to $\sim 29$ masl). (B) Dip-oriented view, showing channelized flow pathways within the HFZ at two elevations in well 85. (C) Strike-oriented view, showing a relatively thin channelized flow zone within the HFZ at well 87 and thicker zone at well 86 .

bounding a cropped portion of the wellfield (Figure 6): one plane is oriented along strike through wells 83 and 88; and the other plane is oriented along dip from well 88 generally southward to the edge of the wellfield (see Figure 1B). The series starts (Figure 6A) shortly after pumping begins at interval $83-\mathrm{H}$ in the HFZ and drawdown has begun to move along strike (with local deviations above and below the depth of the pumping interval), but also has moved rapidly up-dip in the HFZ toward well 87 (e.g., see geometry of up-dip segment of HFZ in Figure 5A) to intersect the dip-direction plane in Figure 6A.

The first interval of well 88 at which drawdown occurs is 88 -I (Figure 6B), consistent with the field testing (Figure 4B). Drawdown moves from $83-\mathrm{H}$ to 88 -I along strike and downward, largely through an intermediate$K\left(\sim 10^{-6} \mathrm{~m} / \mathrm{s}\right)$ route, as shown in the $3 \mathrm{D} K$ view (Figure 6F). Note also that a small portion of the high$K$ HFZ is visible south (up-dip) of well 88 (Figure 6F), which explains the rapid development of drawdown in this area (Figure 6A and 6B).

At progressively later times, simulated drawdown can be traced downgradient to reach observation intervals $\mathrm{J}$, $\mathrm{F}$, and $\mathrm{E}$ in well 88 , in that order (Figure $6 \mathrm{C}$ to $6 \mathrm{E}$ ). Drawdown at 88 -J occurs earlier than was observed during the 83-H test, but the order of drawdown initiation at $88-\mathrm{F}$ and $88-\mathrm{E}$, as well as at $88-\mathrm{G}$ and $88-\mathrm{H}$ (shown in Figure S7), is consistent with the data (Figure 4B). The drawdown progression to the multiple intervals of well 88 follows routes that identify the 3D fracture network within the estimated 3D $K$ distribution, as shown by the white arrows on the visualized drawdown and $K$ in Figure 6. It is not possible to fully identify this fracture network by visualization and inspection of the 3D $K$ distribution, because the large range of $K$ values obscures local small contrasts in $K$ between fractures and surroundings.

Additional details of the complex routes followed by drawdown progressing from $83-\mathrm{H}$ to well 88 are provided in Figures S5 to S7 and accompanying explanations in Appendix S3. Expected fracture geometries and network features that are evident and explained further in the Supporting Information include:

1. linear and planar fracture shapes;

2. multiple connectivity routes to a given location (e.g., to $88-\mathrm{F}$ and $88-\mathrm{J}$ );

3. drawdown movement in multiple directions to ultimately reach some intervals of well 88 (e.g., routes from $83-\mathrm{H}$ going first eastward and then westward to $88-\mathrm{F})$; and

4. high-angle fractures.

It would not be possible to infer these features without 3D HT results.

\section{Particle Tracking to Locate Fast Channelized Paths Through} the Fracture Network

We simulated particle tracking with MODPATH (Pollock 2012) to identify relatively fast channelized 
flowpaths through the wellfield. These paths reveal the portions of the estimated fracture network that are most active for flow. The particle tracking was conducted using four steady-state flow models, each with the estimated 3D $K$ distribution. In the four models, constant-head boundaries were set to produce a hydraulic gradient of 1.0 across the wellfield in the (1) east to west, (2) west to east, (3) north to south, and (4) south to north directions. In each simulated flow field, seven particle tracking simulations were conducted (28 total), each with a grid of starting particles (1 per model cell) placed on a plane parallel to, and at a different distance from, the upgradient constant head boundary (Figure S4). Particles were tracked until they reached an ending plane parallel to the downgradient constant-head boundary. Details of the steady-state models and particle tracking simulations are given in Appendix S2. Models used to conduct the particle tracking are available from Tiedeman and Barrash (2019).

To identify the fastest channelized flowpaths, we postprocessed the particle paths in each of the 28 simulations to extract model cells that meet the following criteria: (1) at least 10 particles travel through the cell (channeling) and (2) each of those particles moves from its starting plane to the ending plane with an average velocity of $\geq 3 \mathrm{~m} /$ day (the fastest paths). This velocity criterion is somewhat arbitrary and depends on the specified effective porosity of 0.001 and the high imposed gradient of 1 ; other velocity criteria did not identify the fracture network as clearly. To identify the active fracture network that reflects multiple forcing conditions, we combined the model cells extracted from the 28 simulations into one set of cells (Figure 7). The coloring of model cells by their estimated $K$ values shows that the fracture network with channelized flow includes high-, intermediate- and even low- $K$ segments (e.g., $K \sim 10^{-8} \mathrm{~m} / \mathrm{s}$ ).

In the deeper part of the wellfield, near wells 83 , 87 , and 88 , a well-defined fracture network is revealed (Figure 7A). It includes: (1) fracture X1 intersecting 88-I and 88-J (Figures 5, S6C and S6D, and S7C and S7D); (2) deep fracture $\mathrm{X} 3$ along strike between wells 85,83 , and 88 (Figures 5 and S7E to S7G); and (3) high-angle fractures connecting the HFZ to $88-\mathrm{I}$ and $88-\mathrm{J}$, which were also identified by tracing drawdown during the 83 $\mathrm{H}$ test (Figures 6 and S6C and S6D). At the depths of the HFZ, two views of a cropped portion of the network are shown (Figure 7B and 7C). Particles are channeled throughout the thick high- $K$ region (Figure 5D) that is estimated at well 86. In contrast, at well 85 , with a higher vertical resolution of drawdown data (see Middle packer configuration in Figures 2 and S2B), the details of the fracture network within the HFZ are revealed (see also Figure 5D), with channeling of flow in the upper and lower expressions of the HFZ, but no flow channeling between (Figure 7B). Well 87 has a relatively thin zone of channelized paths within the HFZ (Figure 7C), consistent with the two closely spaced HFZ expressions in this well (Figure 1D; note Figure 7C also shows deeper fracture $\mathrm{X} 4$ at 87$)$.

\section{Results: Evaluation of Model Fit and Uncertainty}

The ability of the estimated 3D $K$ distribution to explain complex drawdown behavior and identify 3D fracture network geometry, as discussed in the previous sections, is good evidence of the quality of the inversion results. We augment that quality assessment with three metrics: (1) fit to drawdown data for the 42 tests used in the inversion; (2) uncertainty of 3D $K$ estimate; and (3) fit to drawdown data for five tests not used in the inversion.

\section{Calibration Fit}

Simulated and observed drawdown curves at intervals of well 88 for five of the 42 tests used in the inversion are shown in Figure 8 (additional curves are shown in Figure S8). The quality of the fits is representative of that for the 1619 drawdown curves from all 42 tests. Overall, the best fits are for tests conducted in, and observation intervals located in, the upper portion of the wellfield (Figure 8, observation names containing E, F, G, H, and I for tests 86-M, 83-H, 87-G2, and 85-EF). Deeper in the wellfield (observation names containing $\mathrm{J}$ for all tests; all observations for test $87-\mathrm{J} 7$ ), fit quality is mixed. A majority of tests were conducted in the upper part of the wellfield, using packer configurations with a high density of short-length intervals in the upper part and longer intervals in the deeper part (Figure S2). Also, $K$ tends to be larger in the upper part, allowing for higher pumping rates and stronger drawdown responses, which are more informative to the inversion. These factors caused the inversion to better estimate $K$, and thus better fit observations, in the upper part of the wellfield.

Plots of simulated versus observed drawdowns are shown in Figure 9. Plots with linear axes (Figure 9A to 9C) illustrate the fit for drawdowns > approximately $0.1 \mathrm{~m}$. Plots with logarithmic axes (Figure 9D to 9F) better illustrate the fit over the full drawdown range. The fit to all inversion observations shows little bias, with points roughly symmetrical about the 1:1 line, but misfit scatter increases with decreasing drawdown (Figure 9D). Observed drawdown was typically small during pumping tests from lower- $K$ intervals, most of which are in the deeper part of the wellfield. For these tests, we had difficulties with control and measurement of low pumping rates. The poorer fit to small drawdowns is attributed to the likely mismatch between field and model pumping conditions for these tests. The better fit in the upper part of the wellfield is illustrated in Figure 9E, showing a greater density of points near the 1:1 line, compared to substantial scatter at all drawdown magnitudes for deeper observations (Figure 9F).

\section{Uncertainty}

Uncertainty is a measure of relative confidence in the $K$ estimates. Overall, the instrumented well volume has significantly lower uncertainty than uninstrumented margin regions, with an abrupt increase in uncertainty outside the wellfield (Figure 10). This is consistent with 


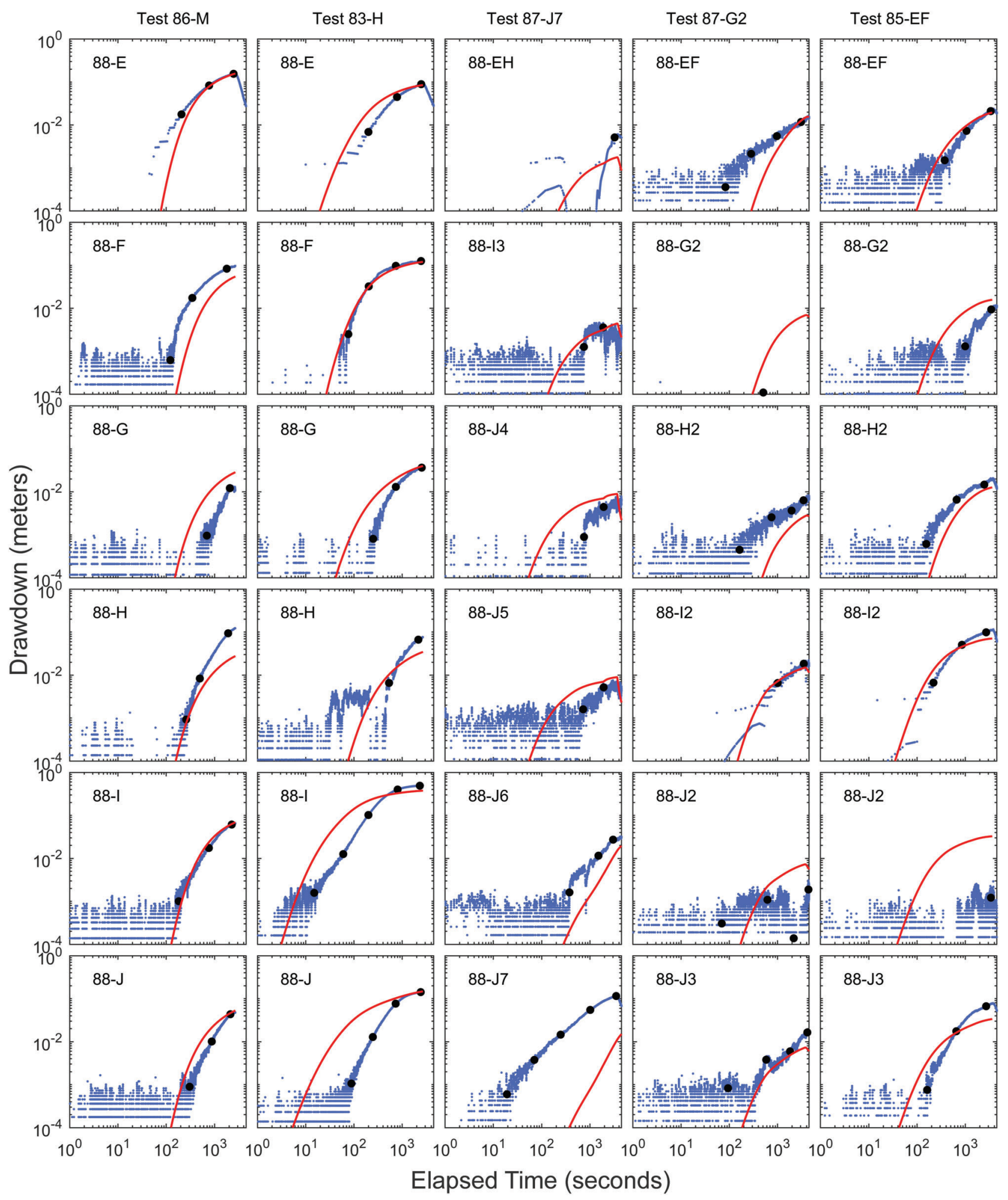

Figure 8. Simulated (red) and observed (blue) drawdown curves at intervals of well 88 for five tests used in the inversion. Black symbols show the inversion observations.

previous HT inversion results (Liu et al. 2002; Cardiff et al. 2013; Hochstetler et al. 2016). Within the wellfield, uncertainty is generally higher in the deeper, low- $K$ portion of the investigated volume (Figure 5) where test and observation density and quality were lower (Figures 2 and S2, Appendix S1).
Fit to Tests Withheld from Inversion

Commonly in HT, validation is conducted to evaluate the predictive capability of the estimated $K$ distribution by assessing the match between simulated and observed drawdowns for tests not used in the inversion (e.g., Berg and Illman 2011; Cardiff et al. 2013; Illman 2014; 
(A)

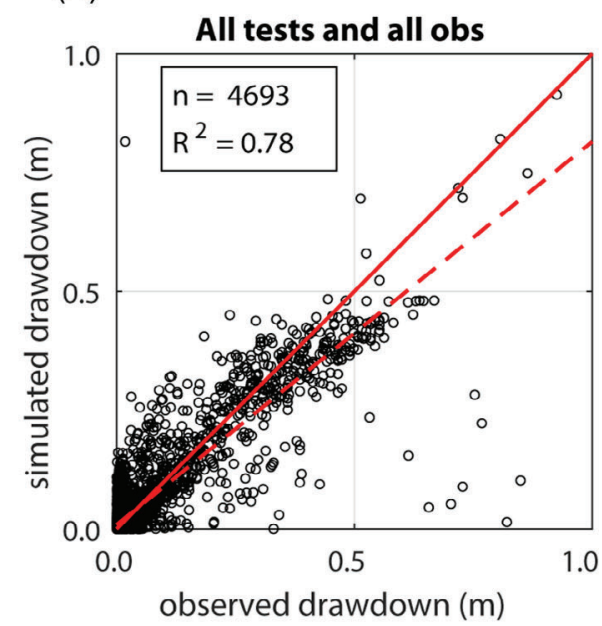

(D)

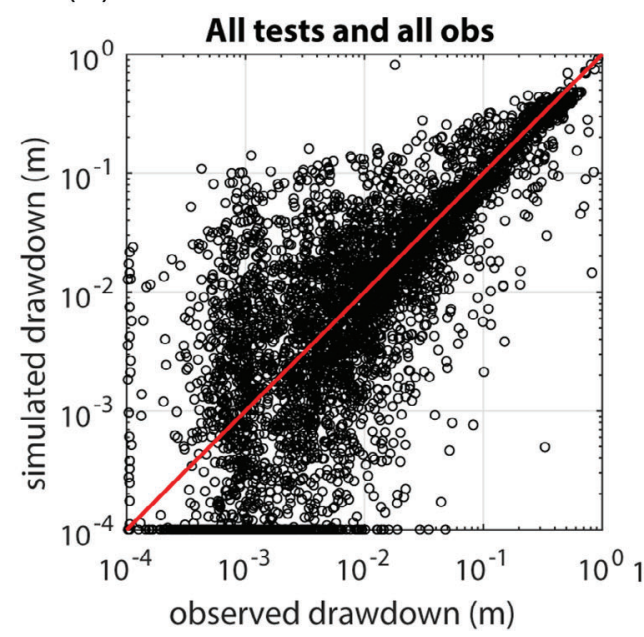

(B)

Tests and obs in upper wellfield

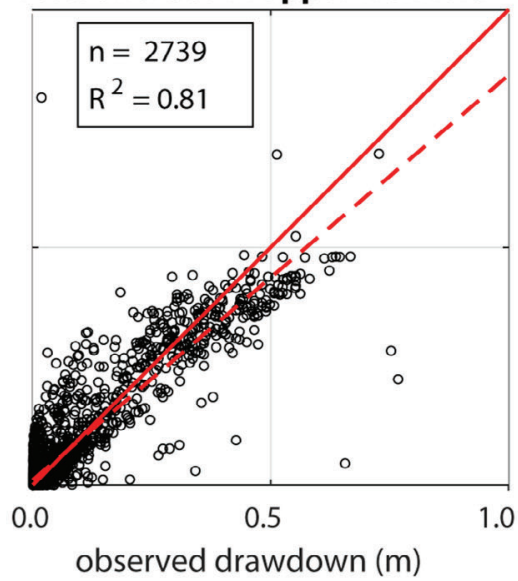

(E)

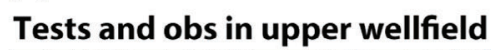

(C)

\section{Tests and obs in lower wellfield}

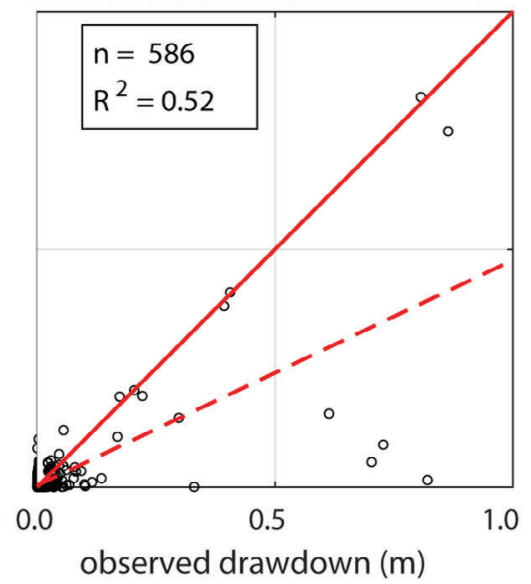

(F)

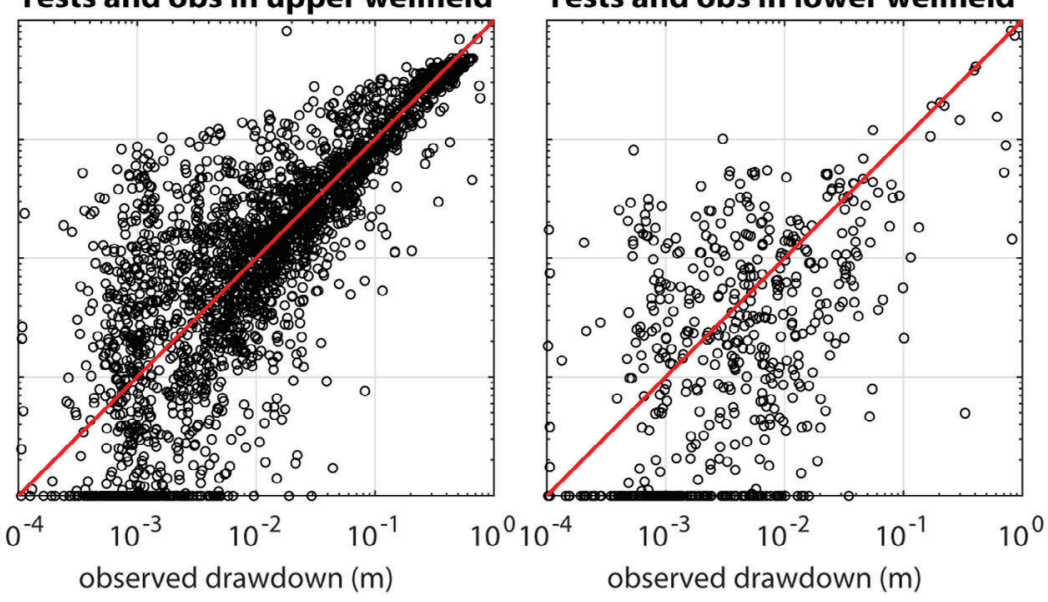

Figure 9. Simulated vs. observed drawdowns, plotted with (A to C) linear and (D to F) logarithmic axes. (A and D) All observations. (B and E) Observations in the upper part of the wellfield for tests conducted in the upper part (observation and test names containing E, F, G, H, I, K, and M). (C and F) Observations in the lower part of the wellfield for tests conducted in the lower part (observation and test names containing J). In (D to F) simulated drawdowns $<10^{-4} \mathrm{~m}$ are plotted as $10^{-4} \mathrm{~m}$. Solid red lines show 1:1 relationship; dashed red lines show best linear fit.

Hochstetler et al. 2016). For our study, the five tests ( $\sim 10 \%$ of 47 available HT tests) withheld from the inversion have similar characteristics as the tests used in the inversion. That is, they have: (1) pumped intervals distributed throughout the wellfield and with a wide range of fracture $K$ and (2) pumping rates and durations similar to those used in the inversion (Table 1, Figures 2 and S2). Thus, they are not true validation tests. The comparison of simulated and observed drawdowns for these tests can instead be considered an incrementally more rigorous quality check on the inversion results, compared to assessing fit for tests used in the inversion. Results show that the match quality for these tests is mostly good to very good overall (Figures 11 and S9), and is comparable to that of the inversion tests (Figures 8 and S8). This is an additional indication that the estimated $K$ field realistically represents the heterogeneity in the wellfield.

\section{Discussion}

\section{Comparison with $K$ Distribution Estimated at Larger Scales}

Characterization of $K$ at the NAWC site scale (100 s of $m$ laterally) (Tiedeman et al. 2010, 2018) and at local high-resolution scale ( $\sim 10 \mathrm{~m}$ laterally, this study) provide complementary information on 3D $K$ structure, heterogeneity, and flow. Differences are primarily due to scale (i.e., of testing, parameter discretization, hydrogeological features) and use of prior information.

Individual mudstone beds at NAWC have been mapped in detail (Lacombe and Burton 2010), and show remarkable lateral continuity over tens to hundreds of meters. Tiedeman et al. $(2010,2018)$ relied heavily on that geologic characterization for delineating the 3D $K$ heterogeneity of site-scale groundwater flow models, by specifying alternating high- and low- $K$ dipping model layers representing different mudstone types. Aquifer 

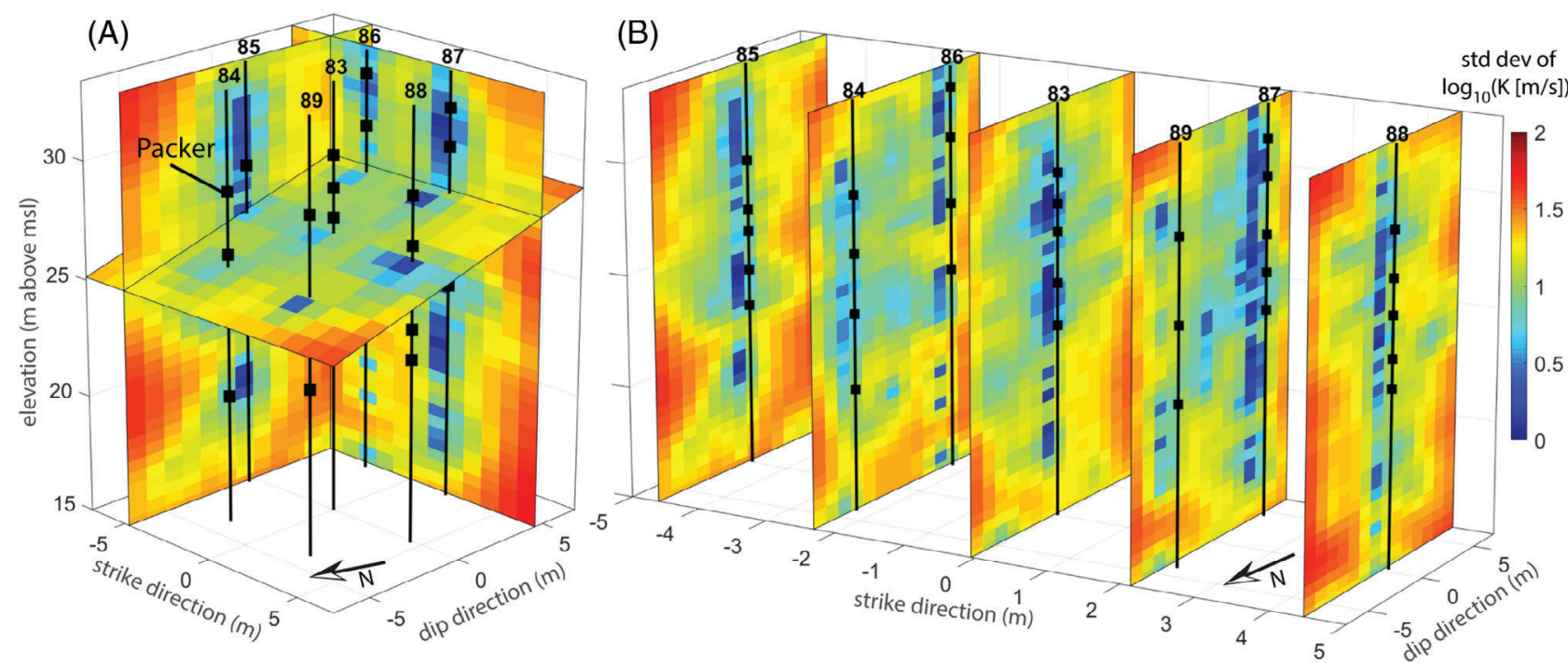

Figure 10. Uncertainty distribution, expressed as standard deviation of $\log _{10}(K)$. Uncertainty increases outside the wellfield and in regions with less pumping and observation coverage or lower quality pumping tests. (A) Same slices as shown in Figure 5A through the $K$ estimation volume. (B) Same slices as in Figure 5D.

tests used to calibrate those models produced drawdown data from sparsely distributed monitor wells typically located tens of meters from the pumping well. These data supported delineation of secondary heterogeneities of $>10 \mathrm{~m}$ length in some areas, such as zones of contrasting $K$ within a dipping layer.

Our HT inversion approach departs from past flow modeling efforts at NAWC by not using prior information on the geology such as knowledge about rock types, bedding dip, or locations of fractures intersecting wells. Omitting geologic prior was deliberate, to evaluate the $K$ features that HT could resolve without such information and to avoid possible bias due to inaccurate priors. The dense spatial distribution of aquifer tests and drawdown observations used for HT inversion allowed for this omission of prior. These data also supported a scale of estimated $K$ variations that is markedly smaller than the $>10 \mathrm{~m}$ features in some parts of the sitescale models, because the entire 83-89 wellfield is $9 \mathrm{~m}$ diameter and the HT inverse modeling discretized $K$ into $1 \mathrm{~m} \times 1 \mathrm{~m} \times 0.5 \mathrm{~m}$ blocks. The HT tests therefore support estimation of the details of moderate- to high- $K$ pathways within and across mudstone beds, whereas the prior structure and more-limited data used to calibrate the site-scale NAWC models supported only a much lowerresolution $K$ distribution.

While the site-scale model does not have the resolution to include 3D fracture network details, the HT model does not have the data support to reliably model flow more than a few meters beyond the 83-89 wellfield. However, the HT model is consistent with the site-scale model in recognizing the presence and importance of features with similar orientations to site-scale bedding such as: (1) the dipping, highly fractured, fissile mudstone interval of the HFZ and (2) along-strike secondary- $K$ fractures (e.g., X2 and X3 in Figure 5). Differences in detail (i.e., below the supported $K$ resolution for the sitescale model) that are significant for flow control in the HT model are: (1) heterogeneity within and between bedding (e.g., Figures 5 and 7B and Figure 2 of Shapiro et al. 2017); (2) cross fractures (Figures 6F and 7A); and (3) the low- $K$ zone that separates the up-dip and down-dip segments of the HFZ (Figure 5).

\section{Consistency of Results with Geologic Data and ERT Results}

The 3D $K$ and fracture network findings are mostly consistent with independent fracture data and ERT results from the 83-89 wellfield. Consistency of the estimated HFZ with fracture data was discussed previously. For the fracture network identified through particle tracking (Figure 7), fracture X3 is consistent with the ATV fracture expressions in wells 83, 85, and 88 at about 20 masl (Figures 1D and S2B). Fracture X4 intersects well 87 at an elevation of about 24 masl, where there are no prominent fractures in the borehole ATV log (Figures 1D and S2A). However, at intervals $87-\mathrm{J} 2$ and $87-\mathrm{J} 4$ at the elevation of $\mathrm{X} 4$, drawdown responses are typically larger than at deeper intervals in the well (see Figure S8), suggesting a hydraulic connection to this depth, and supporting the presence of estimated fracture X4 that connects with the shallower part of the wellfield. Fracture X1 is less supported by the site data. At its elevation in well 88 , there is no prominent fracture and drawdowns are small. The relatively large uncertainty of estimated $K$ at the depth of $\mathrm{X} 1$ in well 88, and in the region where $\mathrm{X} 1$ extends to the south (Figures 5 and 10B), is consistent with this lack of agreement with the site data.

An ERT study conducted in the wellfield imaged pathways through the fractured rock by injecting an electrically conductive tracer into the HFZ at well 87 and extracting it at well 85 (Robinson et al. 2015). ERT 


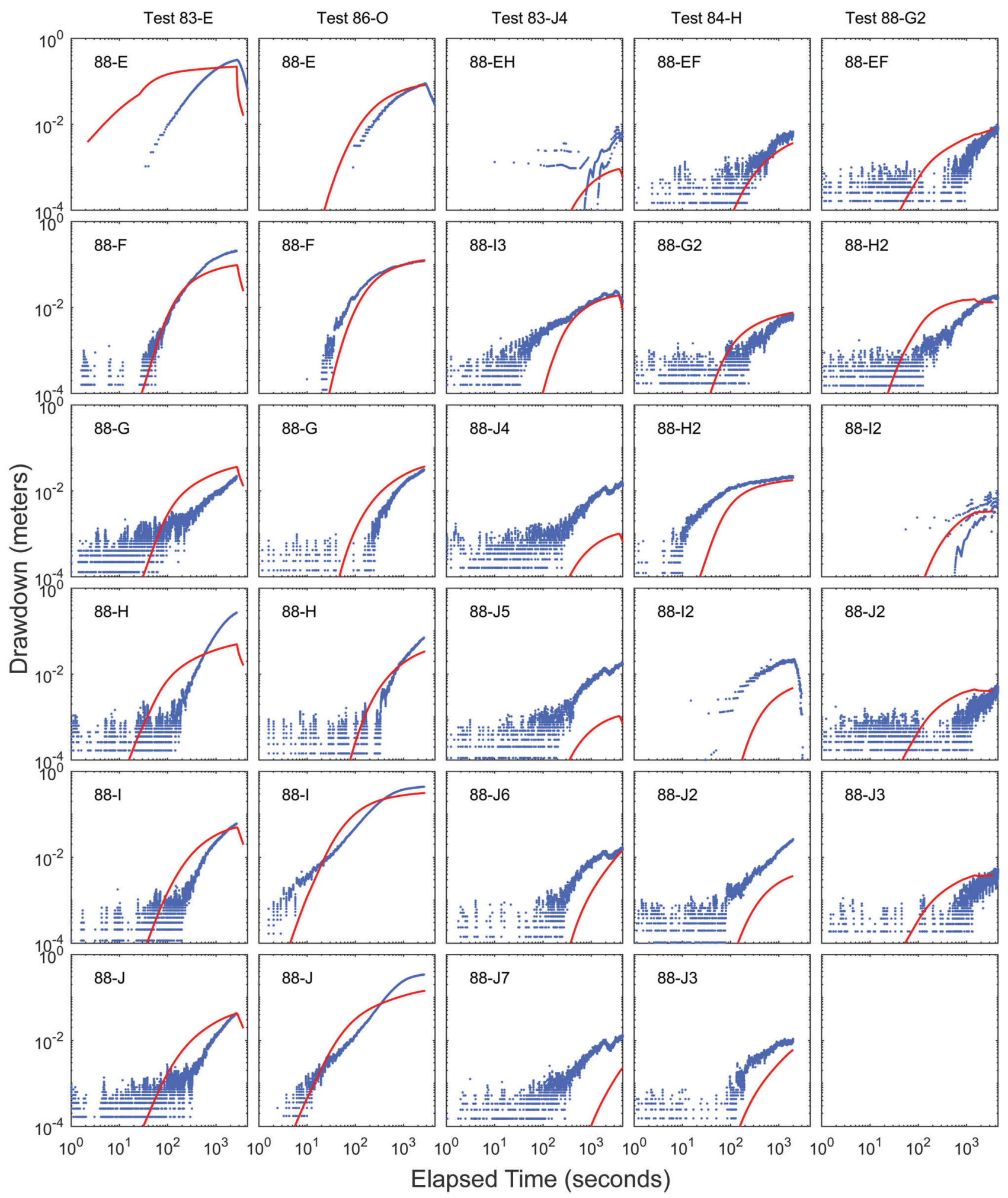

Figure 11. Simulated (red) and observed (blue) drawdown curves at intervals of well 88 for the five tests withheld from the inversion.

imaging showed that the tracer spread out widely from well 87 en route to well 85 , migrating through well 83 but not migrating to well 84,88 , or 89 . This result is consistent with our estimation of an up-dip high-K HFZ that is separated from wells 84,88 , and 89 by a lower- $K$ region.

\section{Robustness of the HT Method for Estimating $K$ in Fractured Rocks}

This first application of HT in a fractured aquifer at HRFS provides insight into the robustness of the method. The HT solution is considered robust, in that it: (1) includes first- and second-order features (in the 3D $K$ 
distribution and fracture network within it) that explain complex drawdown behaviors and (2) locates preferred drawdown and flow paths through a coherent fracture network in a 3D $K$ field with a range of 12 orders of magnitude.

This solution was obtained despite a number of nonidealities in the field testing conditions and data, as well as challenges in the model representation of fractured systems. Nonideal field aspects include: (1) for the lowest $K$ test intervals, difficulty getting "clean" pumping starts and maintaining and measuring low pumping rates and small drawdowns; (2) occasional pressure transients and trends; (3) mixed coverage in terms of packedoff interval density and lengths. Challenging modeling aspects include: (4) forward model cells and inverse model $K$ blocks that include both fractures and rock matrix, and that have difficulty representing high-angle fractures because of block size (yet supported fracture network identification-Figures 6 and 7); (5) difficulty accurately assigning pumping rates and periods, and selecting the inversion observations, for some tests; (6) using a stationary spatial covariance function as regularization for the nonstationary, severe geometry of the fracture network; and (7) extreme $K$ contrasts locally and also in the representation of packers and open intervals in the boreholes.

We suspect the HT solution was robust despite these issues because a sufficient number of tests with high-quality data were conducted from many locations, producing flows in many directions. This high density and variety of "investigation pathways," combined with the geostatistical inversion, supported a coherent solution. Liu et al. (2002) and Cardiff et al. (2013) similarly point to sufficient density of testing and observation as a key reason for higher-quality HT results. Also we note that significant noise reductions (such as for issues 1, 2, 3 , and 5 above) are achievable with relatively minor modifications to experimental techniques and equipment.

\section{HT and Scale of Application}

Here HT is demonstrated in a preexisting wellfield with a $9 \mathrm{~m}$ diameter and an investigated aquifer thickness of 15 to $20 \mathrm{~m}$. However, a larger lateral dimension could likely be investigated, while keeping high resolution, assuming a sufficient number of tests and density of observations. This is supported by previous applications of HT in unconsolidated sedimentary aquifers at HRFS, which produced high-quality results for volumes with land surface diameters similar to the thickness of the investigated aquifer (i.e., $\sim 15 \mathrm{~m}$ for Cardiff et al. 2013 and Hochstetler et al. 2016), using pumping tests only from a central well. This proportion of dimensions from these two HT sites suggests that HT footprints could be larger with the inclusion of tests from perimeter wells also, given sufficient test and observation density to meet site objectives. Ultimately, a trade-off will be reached between larger volume of investigation and "flattening," or loss of vertical resolution, as diameter increases relative to aquifer thickness.

\section{Summary}

In this paper we demonstrate for the first time the capability of HT to estimate 3D $K$ in a fractured aquifer at HRFS; this 3D $K$ inherently "encodes" the fracture network and dynamic connectivity routes through it. The following aspects of HT field testing collectively enabled the estimation of heterogeneity and fracture network details while also supporting a robust solution: modular packers to isolate many borehole intervals for pumping or drawdown observations; high-resolution, fastsampling, small-diameter, FO transducers for drawdown measurements; and sufficient pumping tests from a range of high- and low- $K$ fractures, and from a range of lateral and vertical positions throughout the wellfield.

Forward modeling used a heterogeneous EPM approach to avoid making assumptions about fracture occurrences, dimensions, and properties. Quasi-linear geostatistical inversion was used to estimate the 3D $K$ distribution with: adjoint-state sensitivity calculations; the L-M solution to address nonlinearity; and HPC to facilitate tractable inversion times. The heterogeneous EPM approach, and $K$ block dimensions that are large relative to fracture apertures, yields a 3D $K$ estimate in which fractures are located approximately within coherent, locally higher- $K$ volumes.

The estimated 3D $K$ distribution spans 12 orders of magnitude between low- $K$ unfractured rock matrix and zones with connected high- $K$ bedding-plane fractures. Important hydrogeological features are recognizable by inspection of the 3D $K$ distribution. The 3D fracture network, and connectivity routes through it, are identified by tracing drawdown and by particle tracking. These analyses explain complex drawdown behavior observed in the pumping tests and reveal an otherwise unrecognizable 3D fracture network and connectivity pathways. The 3D $K$ estimate produces a good fit of simulated and observed drawdowns, particularly in the upper part of the wellfield where density of tests and observations was highest.

The capabilities of HT for 3D fractured aquifer characterization at HRFS that are demonstrated in this paper may support applications where heterogeneity confounds the ability to develop and implement scientific and engineering designs. These include improved (perhaps "surgical") in situ remediation design and outcomes (e.g., Leeson et al. 2013; NAS 2015) and larger-scale applications such as for mining, repository assessment, or geotechnical engineering. In addition, 3D HT may provide ground-truth in fractured aquifers for questions about structure of fracturing and heterogeneity and statistics of the $K$ distribution. Finally, HT can provide starting models for further modeling that treats fractures, and the full range of fracture behavior, more accurately.

\section{Acknowledgments}

We thank Colby Thrash and Jeremy Patterson, interns under the USGS-NAGT Program, for their dedicated assistance with HT field testing, and Carole Johnson, 
USGS, for contributing geophysical logs. Support for this work was provided by the USGS Toxic Substances Hydrology Program and a grant from the USGS Innovation Center, and this research used resources provided by the USGS Core Science Analytics, Synthesis, \& Libraries (CSASL) Advanced Research Computing (ARC) group. We thank Peter Kitanidis, Mike Cardiff, and David Hochstetler for helpful discussions. We also appreciate the thoughtful review comments by Matt Becker, Chris Neuzil, and an anonymous reviewer, which significantly improved this article. Any use of trade, firm, or product names is for descriptive purposes only and does not imply endorsement by the U.S. Government.

\section{Supporting Information}

Additional supporting information may be found online in the Supporting Information section at the end of the article. Supporting Information is generally not peer reviewed.

Appendix S1. Supporting details of hydraulic tomography field testing at NAWC.

Appendix S2. Supporting details of forward and inverse modeling.

Appendix S3. Supporting details for visualizations of results.

Table S1. Local coordinates of wells 83-89 at NAWC, and wellhead elevations.

Table S2. Depths of packed-off intervals of wells 83-89.

Figure S1. Photographs of packers and wellhead configurations.

Figure S2. Packer configurations, optical and acoustic televiewer logs, and caliper logs.

Figure S3. Domain, boundary conditions, and discretization for models of pumping tests.

Figure S4. Steady-state model for particle tracking simulations in the west to east direction.

Figure S5. Drawdown isosurfaces and $\mathrm{K}$ distribution in the up-dip portion of the HFZ.

Figure S6. Network and connectivity visualization using drawdown tracing.

Figure S7. Drawdown isosurfaces during pumping test $83-\mathrm{H}$.

Figure S8. Simulated and observed drawdown curves at intervals of wells 83 and 87 for five tests used in the inversion.

Figure S9. Simulated and observed drawdown curves at intervals of well 83 for the five tests withheld from the inversion.

\section{References}

Berg, S.J., and W.A. Illman. 2011. Three-dimensional transient hydraulic tomography in a highly heterogeneous glaciofluvial aquifer-aquitard system. Water Resources Research 47: W10507. https://doi.org/10.1029/2011WR010616

Bohling, G.C., J.J. Butler Jr., X. Zhan, and M.D. Knoll. 2007. A field assessment of the value of steady shape hydraulic tomography for characterization of aquifer heterogeneities.
Water Resources Research 43: W05430. https://doi.org/10 .1029/2006WR004932

Butler, J.J. 2005. Hydrogeological methods for estimation of spatial variations in hydraulic conductivity. In Hydrogeophysics, ed. Y. Rubin, and S.S. Hubbard, 23-58. Dordrecht, The Netherlands: Springer.

Cardiff, M.A., and W. Barrash. 2011. 3-D transient hydraulic tomography in unconfined aquifers with fast drainage response. Water Resources Research 47: W12518. https:// doi.org/10.1029/2010WR010367

Cardiff, M.A., W. Barrash, and P.K. Kitanidis. 2013. Hydraulic conductivity imaging from 3-D transient hydraulic tomography at several pumping/observation densities. Water Resources Research 49: 7311-7326. https://doi.org/10 $.1002 /$ wrcr.20519

Castagna, M., and A. Bellin. 2009. A Bayesian approach for inversion of hydraulic tomographic data. Water Resources Research 45: W04410. https://doi.org/10.1029/ 2008WR007078

Castagna, M., M.W. Becker, and A. Bellin. 2011. Joint estimation of transmissivity and storativity in a bedrock fracture. Water Resources Research 47: W09504. https:// doi.org/10.1029/2010WR009262

Chapman, S.W., B.L. Parker, J.A. Cherry, S.D. McDonald, K.J. Goldstein, J.J. Frederick, D.J.S. Germain, D.M. Cutt, and C.E. Williams. 2013. Combined MODFLOW-FRACTRAN application to assess chlorinated solvent transport and remediation in fractured sedimentary rock. Remediation Journal 23, no. 3: 7-35.

Chen, J., S. Hubbard, J. Peterson, K. Williams, M. Fienen, P. Jardine, and D. Watson. 2006. Development of a joint hydrogeophysical inversion approach and application to a contaminated fractured aquifer. Water Resources Research 42: W06425. https://doi.org/10.1029/2005WR004694

Dafflon, B., W. Barrash, M.A. Cardiff, and T.C. Johnson. 2011. Hydrological parameter estimations from a conservative tracer test with variable-density effects at the Boise Hydrogeophysical Research Site. Water Resources Research 47: W12513. https://doi.org/10.1029/2011WR010789

Darcel, C., O. Bour, P. Davy, and J.-R. de Dreuzy. 2003. Connectivity properties of two-dimensional fracture networks with stochastic fractal correlation. Water Resources Research 39, no. 10: 1272. https://doi.org/10.1029/ 2002WR001628

Day-Lewis, F.D., J.W. Lane, and S.M. Gorelick. 2006. Combined interpretation of radar, hydraulic, and tracer data from a fractured-rock aquifer near Mirror Lake, New Hampshire, USA. Hydrogeology Journal 14, no. 1-2: 1-14.

Deutsch, C.V. 2007. A review of geostatistical approaches to data fusion. In Subsurface Hydrology: Data Integration for Properties and Processes, ed. D.W. Hyndman, F.D. DayLewis, and K. Singha, 7-18. Washington, DC: AGU.

Ehlers, L.J., and M.C. Kavanaugh. 2013. Refining the endgame for groundwater remediation. Groundwater 51, no. 2: $170-174$.

Ellefsen, K.J., P.A. Hsieh, and A.M. Shapiro. 2002. Crosswell seismic investigation of hydraulically conductive, fractured bedrock near Mirror Lake, New Hampshire. Journal of Applied Geophysics 50, no. 3: 299-317.

Ellefsen, K.J., W.C. Burton, and P.J. Lacombe. 2012. Integrated characterization of the geologic framework of a contaminated site in West Trenton, New Jersey. Journal of Applied Geophysics 79: 71-81. https://doi.org/10.1016/j .jappgeo.2011.12.008

Fischer, P., A. Jardani, and N. Lecoq. 2018. Hydraulic tomography of discrete networks of conduits and fractures in a karstic aquifer by using a deterministic inversion algorithm. Advances in Water Resources 112: 83-94.

Goode, D.J., T.E. Imbrigiotta, and P.J. Lacombe. 2014. Highresolution delineation of chlorinated volatile organic compounds in a dipping, fractured mudstone: Depth- and 
strata-dependent spatial variability from rock-core sampling. Journal of Contaminant Hydrology 171: 1-11.

Gustafson, G., B. Gylling, and J.O. Selroos. 2009. The Äspö task force on groundwater flow and transport of solutes: Bridging the gap between site characterization and performance assessment for radioactive waste disposal in fractured rocks. Hydrogeology Journal 17, no. 5: $1031-1033$.

Hao, Y., T.C.J. Yeh, J. Xiang, W.A. Illman, K. Ando, K.C. Hsu, and C.H. Lee. 2008. Hydraulic tomography for detecting fracture zone connectivity. Groundwater 46, no. 2: $183-192$.

Harbaugh, A.W. 2005. MODFLOW-2005, The U.S. Geological Survey modular ground-water model - the ground-water flow process. U.S. Geological Survey Techniques and Methods 6-A16.

Hendricks-Franssen, H.J.W.M., and J.J. Gomez-Hernandez. 2002. 3D inverse modelling of groundwater flow at a fractured site using a stochastic continuum model with multiple statistical populations. Stochastic Environmental Research and Risk Assessment 16, no. 2: 155-174.

Hochstetler, D.L., W. Barrash, C. Leven, M. Cardiff, F. Chidichimo, and P.K. Kitanidis. 2016. Hydraulic tomography: Continuity and discontinuity of high-K and low-K zones. Groundwater 54, no. 2: 171-185. https://doi .org/10.1111/gwat.12344

Illman, W.A. 2014. Hydraulic tomography offers improved imaging of heterogeneity in fractured rocks. Groundwater 52, no. 5: 659-684.

Illman, W.A., X. Liu, S. Takeuchi, T.-C.J. Yeh, K. Ando, and H. Saegusa. 2009. Hydraulic tomography in fractured granite: Mizunami underground research site, Japan. Water Resources Research 45: W01406.

Kitanidis, P.K. 1995. Quasi-linear geostatistical theory for inversing. Water Resources Research 31, no. 10: 2411-2419.

Kitanidis, P.K., and E.G. Vomvoris. 1983. A geostatistical approach to the inverse problem in groundwater modeling (steady state) and one-dimensional simulations. Water Resources Research 19, no. 3: 677-690.

Klepikova, M.V., T. Le Borgne, O. Bour, and J.-R. de Dreuzy. 2013. Inverse modeling of flow tomography experiments in fractured media. Water Resources Research 49, no. 11: $7255-7265$.

Klepikova, M.V., T. Le Borgne, O. Bour, G. Kerry, R. Hochreutener, and N. Lavenant. 2014. Passive temperature tomography experiments to characterize transmissivity and connectivity of preferential flow paths in fractured media. Journal of Hydrology 512: 549-562. https://doi.org/10.1016/j.jhydrol.2014.03.018

Lacombe, P.J., and W.C. Burton. 2010. Hydrogeologic framework of fractured sedimentary rock, Newark Basin, New Jersey. Ground Water Monitoring and Remediation 30, no. 2: $35-45$

Le Borgne, T., O. Bour, M.S. Riley, P. Gouze, P.A. Pezard, A. Belghoul, G. Lods, R. Le Provost, R.B. Greswell, P.A. Ellis, E. Isakov, and B.J. Last. 2007. Comparison of alternative methodologies for identifying and characterizing preferential flow paths in heterogeneous aquifers. Journal of Hydrology 345: 134-148.

Leeson, A., H.F. Stroo, and P.C. Johnson. 2013. Groundwater remediation today and challenges and opportunities for the future. Groundwater 51, no. 2: 175-179.

Linde, N., J. Chen, M. Kowalsky, and S.S. Hubbard. 2006. Hydrogeophysical parameter estimation approaches for field scale characterization. In Applied Hydrogeophysics. NATO Science Series v. 21, ed. H. Vereecken, A. Binley, G. Cassiani, A. Revil, and K. Titov, 9-44. New York: Springer.

Liu, S., T.-C.J. Yeh, and R. Gardiner. 2002. Effectiveness of hydraulic tomography: Sandbox experiments. Water
Resources Research 38, no. 4: 1034-5-9. https://doi.org/ 10.1029/2001WR000338

Martinez-Landa, L., and J. Carrera. 2005. An analysis of hydraulic conductivity scale effects in granite (full-scale engineered barrier experiment [FEBEX], Grimsel, Switzerland). Water Resources Research 41: W03006. https://doi .org/10.1029/2004WR003458

Martinez-Landa, L., and J. Carrera. 2006. A methodology to interpret cross-hole tests in a granite block. Journal of Hydrology 325: 222-240.

Mettier, R., G. Kosakowski, and O. Kolditz. 2006. Influence of small-scale heterogeneities on contaminant transport in fractured crystalline rock. Groundwater 44, no. 5: 687-696.

NAS. 2015. Characterization, Modeling, Monitoring, and Remediation of Fractured Rock, 244. Washington, DC: National Academies Press.

Nowak, W., and O.A. Cirpka. 2004. A modified LevenbergMarquardt algorithm for quasi-linear geostatistical inversing. Advances in Water Resources 27: 737-750.

NRC. 2013. Alternatives for Managing the Nation's Complex Contaminated Groundwater Sites, 422. Washington, DC: National Academies Press.

Paillet, F.L. 1998. Flow modeling and permeability estimation using borehole flow logs in heterogeneous fractured formations. Water Resources Research 34, no. 5: 997-1010.

Pollock, D.W. 2012. User guide for MODPATH version 6-A particle-tracking model for MODFLOW. In U.S. Geological Survey Techniques and Methods Book 6, chapter A41. Reston, VA: U.S. Geological Survey. 58 pp.

Quinn, P.M., J.A. Cherry, and B.L. Parker. 2016. Depth-discrete specific storage in fractured sedimentary rock using steadystate and transient single-hole hydraulic tests. Journal of Hydrology 542: 756-771.

Reeves, D.M., D.A. Benson, and M.M. Meerschaert. 2008. Transport of conservative solutes in simulated fracture networks: 1. Synthetic data generation. Water Resources Research 44: W05404. https://doi.org/10.1029/ 2007WR006069

Renard, P., and D. Allard. 2013. Connectivity metrics for subsurface flow and transport. Advances in Water Resources 51: $168-196$.

Robinson, J., L. Slater, T. Johnson, A. Shapiro, C. Tiedeman, D. Ntarlagiannis, C. Johnson, F. Day-Lewis, P. Lacombe, T. Imbrigiotta, and J. Lane. 2015. Imaging pathways in fractured rock using three-dimensional electrical resistivity tomography. Groundwater 54, no. 2: 186-201.

Rubin, Y., and S.S. Hubbard. 2005. Stochastic forward and inverse modeling: The "hydrogeophysical" challenge. In Hydrogeophysics, ed. Y. Rubin, and S. Hubbard, 487-511. Dordrecht, The Netherlands: Springer.

Rutqvist, J., and O. Stephansson. 2003. The role of hydromechanical coupling in fractured rock engineering. Hydrogeology Journal 11: 7-40.

Sandve, T.H., E. Keilegavlen, and J.M. Nordbotten. 2014. Physics-based preconditioners for flow in fractured porous media. Water Resources Research 50: 1357-1373. https:// doi.org/10.1002/2012WR013034

Shapiro, A.M., C.E. Evans, and E.C. Hayes. 2017. Porosity and pore size distribution in a sedimentary rock: Implications for the distribution of chlorinated solvents. Journal of Contaminant Hydrology 203: 70-84.

Soler, J.M., J. Landa, V. Havlova, Y. Tachi, T. Ebina, P. Sardini, M. Siitari-Kauppi, J. Eikenberg, and A.J. Martin. 2015. Comparative modeling of an in situ diffusion experiment in granite at the Grimsel test site. Journal of Contaminant Hydrology 179: 89-101.

Somogyvári, M., M. Jalali, S. Jimenez Parras, and P. Bayer. 2017. Synthetic fracture network characterization with transdimensional inversion. Water Resources Research 53: 5104-5123. https://doi.org/10.1002/2016WR020293 
Tiedeman, C.R. and W. Barrash. 2019. MODFLOW-2005 and MODPATH models used to simulate hydraulic tomography pumping tests and identify a fracture network, former Naval Air Warfare Center, West Trenton, NJ. U.S. Geological Survey data release. https://doi.org/10.5066/ P9QUV0TS.

Tiedeman, C.R., P.J. Lacombe, and D.J. Goode. 2010. Multiple well-shutdown tests and site-scale flow simulation in fractured rocks. Groundwater 48, no. 3: $401-415$.

Tiedeman, C.R., A.M. Shapiro, P.A. Hsieh, T.E. Imbrigiotta, D.J. Goode, P.J. Lacombe, M.F. DeFlaun, S.R. Drew, C.D. Johnson, J.H. Williams, and G.P. Curtis. 2018. Bioremediation in fractured rock: 1 . Modeling to inform design, monitoring, and expectations. Groundwater 56, no. 2: $300-316$.

Tiedeman, C.R., W. Barrash, C. Thrash, and J. Patterson. 2019. Pumping rate, drawdown, and atmospheric pressure data from hydraulic tomography experiment at the former Naval Air Warfare Center, West Trenton, NJ, 2015-2016, U.S. Geological Survey data release. https://doi.org/10.5066/ P95XFIYV.

Trottier, N., F. Delay, O. Bildstein, and P. Ackerer. 2014. Inversion of a dual-continuum approach to flow in a karstified limestone: Insight into aquifer heterogeneity revealed by well-test interferences. Journal of Hydrology 508, no. 0: $157-169$.
Wang, X., A. Jardani, H. Jourde, L. Lonergan, J. Cosgrove, O. Gosselin, and G. Massonnat. 2016. Characterisation of the transmissivity field of a fractured and karstic aquifer, southern France. Advances in Water Resources 87: $106-121$

Wellman, T.P., and E.P. Poeter. 2006. Evaluating uncertainty in predicting spatially variable representative elementary scales in fractured aquifers, with application to Turkey Creek basin, Colorado. Water Resources Research 42: W08410. https://doi.org/10.1029/2005WR004431

Wellman, T.P., A.M. Shapiro, and M.C. Hill. 2009. Effects of simplifying fracture network representation on inert chemical migration in fracture-controlled aquifers. Water Resources Research 45: W01416. https://doi.org/10.1029/ 2008WR007025

Wishart, D.N., L.D. Slater, and A.E. Gates. 2008. Fracture anisotropy characterization in crystalline bedrock using field-scale azimuthal self potential gradient. Journal of Hydrology 358: 35-45.

$\mathrm{Xu}, \mathrm{C}$., and P. Dowd. 2010. A new computer code for discrete fracture network modelling. Computers and Geosciences 36: $292-301$.

Zha, Y., T.-C.J. Yeh, W.A. Illman, T. Tanaka, P. Bruines, H. Onoe, and H. Saegusa. 2015. What does hydraulic tomography tell us about fractured geological media? A field study and synthetic experiments. Journal of Hydrology 531: $17-30$.

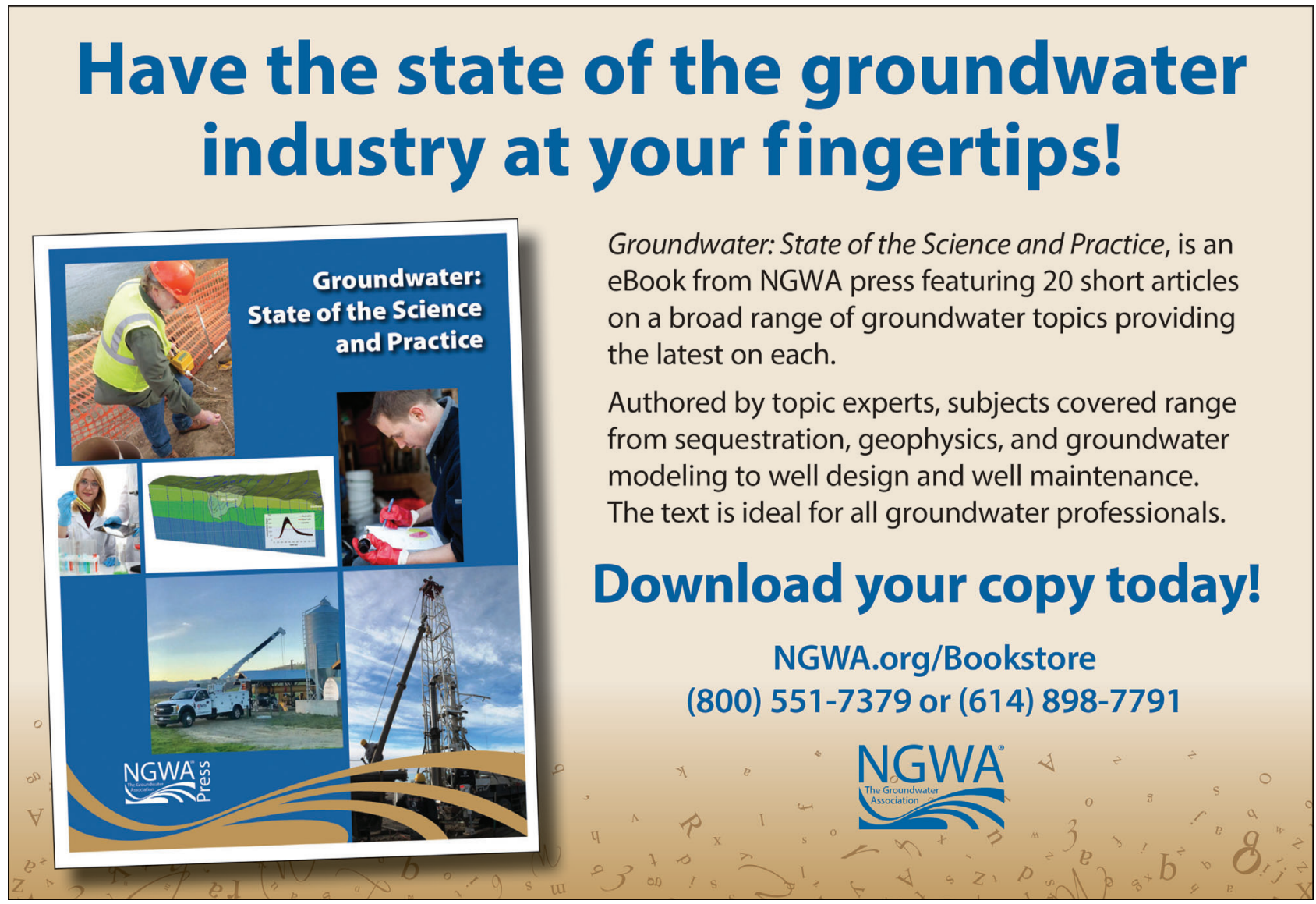

